\title{
Six
}

\section{NATURALISTIC COGNITIVISTS}

But what the Assessor says in Either-Or is also true: that the more exquisite the drink one succumbs to, the more difficult the cure. And now to have fallen prey to 'science.' Merciful God, it would require a world revolution to drag a man out of this drunkenness. Søren Kierkegaard, Journals, 1850.

The semi-cognitivists are conscious of this value dilemma: Either value is fact or value is not fact; if value is fact it can be known, but this knowledge is not valuational; if value is not fact its knowledge would be valuational, but there is no such knowledge. In the first case, value cannot be known; in the second case, value cannot be known. In both cases, value cannot be known.

Yet, the semi-cognitivists do not despair of the possibility of value knowledge, as do the non-cognitivists; still, they do not throw themselves wholeheartedly into the search for it, as do the cognitivists. They do so only halfheartedly. They drag their feet, shackled as they are by positivistic chains. For them the dilemma is unsolvable, except by piecemeal unraveling of individual situations. They do not take the dilemma by the horns, nor do they escape between the horns. They do acknowledge the alternatives of the dilemma - but they, so to speak, break off one horn. They say value knowledge is possible, but their "knowledge" has none of the characteristics usually meant by "knowledge."

The cognitivists have no such restraints. They throw themselves wholeheartedly into the search and attempt to solve the dilemma in two possible ways, taking it by the horns. The naturalists take it by one horn, the non-naturalists by the other. Both acknowledge the alternatives of the dilemma, but each denies one of the consequences. For the naturalists, value is fact, and hence factual knowledge is value knowledge. In a sense, the naturalists escape between the horns by not acknowledging any dilemma at all. For if value is fact then value is not non-fact, and there is no dilemma. For the non-naturalists, value is not fact, but value knowledge is possible. The naturalists regard value and fact as essentially alike; hence, value knowledge is essentially like factual knowledge, and they propose that factual knowledge is value knowledge. The non-naturalists regard value and fact as essentially different; hence, value knowledge is essentially different from factual knowledge, and they construct factual knowledge.

Although naturalists do not acknowledge the positivistic position, they fulfill the positivistic program, not out of necessity as do the positivists, but out of conviction. The positivists hold that since value sentences are not propositions, wherever values appear in propositions, these propositions belong to some naturalistic science such as psychology, sociology, and the like. Thus, the naturalistic sciences appear willy-nilly because value sciences are impossible. The naturalists are less sensitive 
than either the positivists or the non-naturalists; they do not see any essential difference between fact and value expressions. While positivists drown value knowledge in fact knowledge out of necessity, because there is no other alternative, naturalists do the same out of inclination, because for them value is fact and fact is value. Positivists see value, but it does not fit into their world; they kill it in self-defense, in order to keep their sanity. Naturalists run over it by accident; they do not see it at all; they commit manslaughter. For both, value is a kind of freak, indeed, a monstrosity, fitting in nowhere, like a wolf child. Neither treat it as human. Positivists do see that it is human, but they throw it to the wolves because they see no way of fitting it for human company. Naturalists also throw it to the wolves, but they do it in a more straightforward fashion - they think it is a wolf. Thus they are not plagued by the stings of conscience that rack the positivists and make them explode into ever new camps of freakish theories to account for the freak - ever more of those "strangest aberrations ever to visit the mind of man," to speak with C. I. Lewis. ' The conscience of the naturalists is clear, simple, clean, and more naive. They do not hear its voice at all, while the positivists do hear it and try to appease it with all kinds of rationalizations. Their semi-cognitivist theories thus may be called rationalizing rather than rational. The cognitivist theories of the naturalists are rational, but, unfortunately, they are not about value.

Only non-naturalistic cognitivists see clearly the peculiar nature of value and attempt fully to understand and account for it - to make for value a home within the confines of human rationality; but many of them, too, suffer from inherent inconsistencies. They do not secularize value empirically, but they hypostatize it ontologically.

Neither the naturalists nor the non-naturalists have so far been able to solve the value problem. Naturalists know what is not value; non-naturalists know not what is value. They mutually obvert, but they do not solve the value problem. The naturalists, as Paul Kecskemeti ${ }^{2}$ pointed out, behave unscientifically in the name of science, the non-naturalists scientifically in the name of intuition. Note that for Kecskemeti the teleological position is non-naturalistic, while for Moore it is naturalistic. Neither naturalism nor non-naturalism "has an advantage in terms of hardheaded, empiricist toughness." Neither, as Arthur N. Prior has shown, is capable of proof. The naturalistic fallacy, in this respect, is no fallacy. As long as no definition exists to give the meaning of "natural" or "non-natural,"as applied to characteristics, naturalists may well define "good" as the natural property $x$, say, "pleasantness," without committing a fallacy if only they do not hold that what they are doing is Ethics-but rather Hedonics or the like-or explain why and in what respect what they do is Ethics. But they cannot have their naturalistic cake and eat Ethics too.

What these people plainly like to hold is that goodness is both identical with pleasantness and not identical with it; and, of course, it cannot be done. They want to regard 'What is pleasant is good' as a significant assertion; and it can only be so if the pleasantness of what is pleasant is one thing, and its goodness another. On the other hand they want to make it logically impossible to contra- 
dict this assertion-they want to treat the opposing assertion that what is pleasant may not be good as not merely false but logically absurd — and this can only be done if pleasantness and goodness are taken to be identical. ${ }^{3}$

Against such inconsistent naturalists-and most of them are-Moore's argument, says Prior, is valid; but Moore's argument does not logically prevent any naturalistic ethics. The non-naturalist cannot refute the naturalist by simple assertion, as little as the naturalist can the non-naturalist. Thus, what is needed on both sides is definition. Since this is a cognitivist requirement, the solution of the naturalist-non-naturalist dilemma presupposes the cognitivist position. No semi-cognitivist position, least of all the Oxford School with its militant stand against definition, can solve it. Both naturalists and non-naturalists are, thus, inherently, cognitivists.

This means that both of them affirm the propositions that (1) there is value, (2) it can be known, and (3) knowledge consists of systematization. But almost every word, "value," "known," "systematization," has a different meaning for them. The cognitivists are divided both ontologically and epistemologically, both as to their view of the nature of value, and the nature of value knowledge. For this reason, I will divide both naturalists and non-naturalists into empiricists and formalists, depending on whether the nature of value or the nature of value knowledge is their primary concern. In general, the empiricists are less precise in their methodological analysis and content themselves with propositions (1) to (3), while the formalists go on to propositions (4) and (5) - that systematization is formal, based on axiomatic formulation and deductive expansion of the essence of the value experience, and that a value system proves itself by the scope of its applicability to the value world. In general, also, non-naturalists are more formalistic than naturalists and more inclined to accept all five propositions. The naturalists share with the semi-cognitivists their anti-systematic bias. Their view of systematization is inductive and empirical rather than deductive and a priori. Thus, a non-formal non-naturalist is apt to be more formally inclined than a formal naturalist.

The naturalists are, then, closer to the semi-cognitivists, who are regarded by some writers as linguistically disguised naturalists. Naturalists are divided in two groups, empiricists and formalists; the first attempt to find value in the subject matter, the second in the method, of the natural sciences. The empiricists commit the naturalistic fallacy, while the formalists are apt to commit the metaphysical fallacy.

\section{Naturalistic Empiricists}

This is the naturalistic position in the narrow sense. When speaking of "naturalists," we usually mean material rather than formal naturalists. A systematic treatise on material naturalism would investigate the materials of the various natural and social sciences and examine how they are related to whatever is regarded as the subject matter of Ethics. The only existing treatise of this kind, Abraham Edel's, ${ }^{4}$ discusses the relationships between the social sciences and ethics. Ethics, Edel believes, can 
reach no stricter systematization than these sciences have reached. He is forced to content himself with keeping the concept of good as an "open" (a euphemism for "vague") concept, and to limit himself to partial modes of defining. An ultimate definition of "good" and "ought," he believes, depends on getting a complete picture of the nature of human beings, their cognitive faculties and social relations. Since this is not yet available, he uses as a working conception a notion of good that has to do with the direction of human striving and regards evil as the object of an aversion. ${ }^{5}$

Here we have the Wittgensteinian result reached on an empirical rather than a methodological basis. While in Wittgenstein we have a conscious renunciation of phenomenal penetration and hence of essential definition, with the Edelian naturalist we have a pragmatic renunciation: things are not yet ripe for valuational insight; we have to play on the surface of the phenomena, for the sciences have not yet defined for us our subject matter. The cognitivist position of the naturalist serves as efficiently for stopping the value enterprise as the position of the semi-cognitivist. While semicognitivists put all kinds of gimmicks on the drill of phenomenal penetration"logical oddity," "indication," and such — which stop it from going too deeply into the subject, naturalists leave the drill unencumbered but stop it when it meets a certain rather loose and shallow layer, the phenomena of social science, believing that this is what they seek, if only they wait a few geological ages for it to solidify.

Both semi-cognitivism and naturalistic cognitivism are half-hearted efforts; if the naturalists lack the positivistic shackles that weigh down the semi-cognitivists, they also lack the wings of inspiration and power of insight that characterize the true scientific explorer or scientist-philosopher, such as Dr. John Locke. Locke- - before this very same problem, "the principle of morals"-thought that material inquiries "took a wrong course; and that before we set ourselves upon enquiries of that nature it was necessary to examine our own abilities and see what objects our understanding were, or were not, fitted to deal with." It is peculiar that for morals he advocated the opposite method he advocated for natural science, and that the historical development of both followed the opposite course to the one he advocated. The literature of naturalistic cognitivism is the outcome of this doubly inverted development, based as it is on Locke's recommendations for natural science, and opposed to his recommendations for ethics.

Although Edel is not prepared to follow the analogy of science and ethics down to its methodological roots, he does his best to fortify his argument against nonnaturalists, cementing, as it were, his drilling hole and strengthening it against collapse in case someone pokes holes in it and asserts that what it leads down to is not value at all but fact. The "unbridgeable chasm" between "is" and "ought," he says, is nothing but unduly blowing up a limited logical proposition, namely, that a judgment of value cannot be derived from a judgment of fact.

It is true, roughly speaking, that a categorical assertion containing a given term does not follow validly from premises which do not contain the term. No 
conclusions about what ought to be or what is good can be drawn from premises solely about what is. ${ }^{6}$

But this is not different from syllogisms. No conclusion that Socrates is mortal can be drawn simply from the premise that all men are mortal; that Socrates is a man must be added, thus introducing the term 'Socrates' into the premises. All the laws and observations of physics and astronomy could not serve to deduce that an eclipse will take place unless some premise defining the term 'eclipse' is introduced, or some rule for its use provided. This warrants no conclusion that an eclipse is a non-physical phenomenon, with overtones of suspicion that it may be an instrument of Zeus or else a human fiction! Similarly we cannot on this logical ground alone proclaim the uniqueness of Socrates. And so nothing is established likewise about the independence of value and fact.'

It is, therefore, legitimate to survey the social and psychological sciences and examine their relevancy for valuation. This material enrichment of value theory, Abraham Edel believes, will eventually point the way to a solution of formal problems. In my view, this is putting the cart before the horse. Before using the contents of natural science as relevant to ethics, the method of natural science must be analyzed and applied to a possible method of value science. ${ }^{8}$ The subjects of ethics-moral life and death, love and hate, justice and liberty - are far more complex, subtle, and intricate than those of natural science; yet, the methodological tools proposed to deal with them by naturalists of Edel's type - the tools of the social sciences-are far more simple, naive, and unsophisticated than those of natural science - almost as much more simple as the phenomena they are supposed to deal with are more complex. It seems odd - methodologically odd - to expect a "scientific" account of a more complex subject matter by a less complex method. This methodological oddness, based on lacking understanding of the difference between analytic and synthetic methods, is the common characteristic of all material naturalists. Edel, in Science and the Structure of Ethics, does not discuss the methodological difference between science and philosophy or the axiomatic nature of science. As a result, he confuses linguistic analysis with formalization, misunderstands the relation between ethics and axiology, and regards confusions of analytic and synthetic procedures, such as Jeremy Bentham's and others', as measurement. ${ }^{9}$

While Edel's survey of the whole field of the social and psychological sciences leaves the concept of value "open," Maxime Glansdorff, ${ }^{10}$ after a similar survey, lands firmly on one science as indicative of the locus of value. His emphasis is partly anti-metaphysical in order to counteract the deep metaphysical current in continental value theory. Value is a general qualification of things that are not indifferent. This presupposes, first, the mental representation of an object, and second, our being affected by the thing valued. We give things value not simply because we represent them, but also because they impress us. Value is a condition not only of the intellectual but also of the affective order. The analysis of the affective qualities of consciousness leads Glansdorff to the result that the theory of value is nothing but a part 
of the biological theory of adaptation. Value is, in various degrees, the flowering of consciousness. It is more than an idea and more than an emotion. It is a synthesis of the psychic life capable of uniting the highest thoughts with the deepest affections. It is the integral reality of the human spirit, the state of integral awareness of consciousness. Since consciousness is aware in proportion to the lack of adaptation of human beings to their environment, that is, the conditions which surprise them agreeably or disagreeably and mobilize more or less their nervous apparatus, value is a consequence not of an adaptation to circumstances or a harmony between self and the world, but on the contrary of a non-adaptation more or less varied. The richness of the spiritual life thus depends on the imperfection of human nature.

For Glansdorff, a value judgment is an expression of value as a psychic fact. The essential condition of the judgment of value is comparison, that is, the mental act of comparing between the object of a tendency and that of an actual incident. Indifference ceases, the subject leaves its neutrality either positively when it approves the change that an incident has brought about, or negatively when it disapproves. The comparison between the object of the tendency and that which has brought about the incident is teleological. It is so not only when someone says " $X$ is better than $Y$," but also when someone says " $X$ is good." When I say that "Butter is better than margarine," the essential nature of my judgment resides in a rapport of more general and more fundamental character than the comparison of the object butter with the object margarine. It resides in the character of the object to which both are compared, namely, that of a tendency derived from my alimentary habits. If I say that "Butter is better than margarine," it is because butter is more in conformity with the object of this tendency of mine than margarine. Thus, a value judgment is always a comparison of certain objects with the object of a tendency. The same comparison exists when I simply say that a thing is good. (In terms of formal axiology, Glansdorff analyzes both "better" and "good" as "good for me." II) In this case I confirm that the thing in question corresponds to the object of that tendency. Hence, all value judgments are both positive and comparative. This fundamental view of value the author applies to aesthetics, economics, ethics, and other value sciences. In economics, value is active and concerns more the finality than the existence of the things valued. In aesthetics, value is contemplative, comprehending things more in their being than in their becoming. In ethics, the two viewpoints are combined; moral value is a synthesis of the active and the contemplative. The moral ideal is regarded as beautiful in its spiritual existence while it is regarded as morally good when seen in the perspective of finality.

This profound analysis makes the best of an analytic concept and translates a characteristic aspect of French ontological thought - the efficacy of the negative, which we find in Sartrean as well as throughout French axiological metaphysicsinto terms of a naturalistic pattern. For all this, the argument shares the failure of all analytic thinking: it gives hints rather than insights, for the explicatory terms, "finality," "being," "becoming," and so on, are as vague as the terms being explained. 
While Glansdorff sees the locus of value in the consciousness of adaptation, Gosta Carlberg ${ }^{12}$ finds it in human conscience, psychologically understood. He bases his work on the psychological investigations of Abraham Maslow - both Maslow's book ${ }^{13}$ and his articles collected in book form ${ }^{14}$ after Carlberg's essay appeared; and he develops them philosophically. Although the value in question is ethical rather than biological - the value of persons in their physical-spiritual self-fulfilment-it has axiological overtones in its rational approach to the problem.

In Werner Wolff' ${ }^{15}$ approach, the problem of the uniqueness of the valueconsciousness of each person is solved by focusing on the singular frame of reference that gives each incident in a person's life its position and meaning within the whole of the individual pattern. His "existential psychology" interprets the data in terms of this unique value pattern, in contrast to the various interpretations of analytic psychology that put all human manifestations into conceptual straitjackets. On the basis of his psychology of values, Wolff fashions a therapy that makes the individual discover his own value pattern and recreate his values. In Stephan Strasser's work ${ }^{16}$ we find a phenomenological superstructure for Wolff's inductive procedure. Together these two studies are prolegomena for the systematic structuring of intrinsic valuation. They demand comparison with the relevance of positivistic "therapy" for the value experience, with psychologically based value theories proposed by philosophers such as Maria Ossowska and Bertrand Russell, and with value theories based on various aspects - phenomenological, teleological, hedonic —of psychological experience, such as Maurice Mandelbaum's, Albert L. Hilliard's, and others.

Maria Ossowska, ${ }^{17}$ after rejecting psychological hedonism, gives a detailed analysis of experiences connected with the moral life-moral sense, conscience, remorse, feelings of guilt, and the like - and thus illuminates the twilight realm between psychology and ethics from the side of philosophy as Wolff and Strasser do from the side of psychology. All three works make clear that this realm cannot be defined by empirical description, ${ }^{18}$ but only by formal insight and axiomatic construction. Only thus will the phenomena perceptively described by these writers find their common frame of reference and their precise systematic position within the whole of axiology as well as within the specific realm of axiological psychology.

Bertrand Russell ${ }^{19}$ psychologizes the analytic concept "choice" and links it to "desire." Any state of affairs has an intrinsic quality that inclines us to choose it or not to choose it. He calls this intrinsic quality good when we incline to choose it and bad when we incline to reject it. In an inanimate world, nothing would be either good or bad. Hence, the definition of "good" must involve desire. Russell suggests that an occurrence is good when it satisfies desire or, more precisely, that we may define "good" as "satisfaction of desire." An occurrence is better than another if it satisfies more desires or a more intense desire. He does not pretend "that this is the only possible definition of good but only that consequences will be found more consonant with the ethical feelings of the majority of mankind than those of any other theoretically defensible definition." ${ }^{20}$ 
The objection that some desires are bad, and that their satisfaction is a further evil, Russell meets by the notion of compossibility of desires. If A desires that B should suffer, and succeeds in satisfying his desire, the whole state of affairs is not good, and the definition does not imply that it is. B's desires are not satisfied, and A's satisfaction is a source of dissatisfaction to others. A's and B's desires are incompatible. There can be a greater total of satisfaction of desire where desires are compossible than where they are incompatible.

This leads to an ethics by which desires may be distinguished as right or wrong, or, speaking loosely, as good and bad. Right desires will be those that are capable of being compossible with as many other desires as possible; wrong desires will be those that can only be satisfied by thwarting other desires. Usually when an act is right, according to the definition, it is one toward which we feel the emotion of approval; and when it is wrong, it is one toward which we feel disapproval. Surveying the acts that arouse emotions of approval or disapproval, we find that, as a general rule, the acts that are approved of are those believed likely to have, on balance, effects of certain kinds, while opposite effects are expected from acts that are disapproved. Effects that lead to approval are defined as "good," and those leading to disapproval as "bad." An act of which, on the available evidence, the effects are likely to be better than those of any other act that is possible in the circumstances, is defined as "right"; any other act is "wrong." What we "ought" to do is, by definition, that act which is right. It is right to feel approval of a right act and disapproval of a wrong act. These definitions and propositions, Russell believes, if accepted, provide a coherent body of ethical propositions that are true (or false) in the same sense as if they were propositions of science. Reason in valuation, thus, is a subject of exact inquiry. But "reason," in this context, has precisely limited meaning. "It signifies the choice of the right means to an end that you wish to achieve. It has nothing whatever to do with the choice of ends." ${ }^{21}$ The latter is irrational.

Desires, emotions, and passions are the only possible causes of action. Reason is not a cause of action, but only a regulator. If I wish to travel by plane to New York, reason tells me that it is better to take a plane which is going to New York than one which is going to Constantinople. I suppose that those who think me unduly rational consider that I ought to become so agitated at the airport as to jump into the first plane that I see, and when it lands me in Constantinople I ought to curse the people among whom I find myself for being Turks and not Americans. This would be a fine, full-blooded way of behaving, and I would, I suppose, meet with the commendation of the critics $^{22}$

who tell Russell "over and over again" that he overestimates the part of reason in human affairs.

Again, this is an ingenious elaboration of some analytic concepts; yet, the total is somewhat of a hodgepodge. What is the exact relation between choice and desire? Between compossibility and incompatibility? Between "good" as the intrinsic quality 
of leading to choice, and "good" as effects leading to approval? Between the "ought" that refers to right acts, and the "ought" that bids us do "good"? What are the definitions of moral, social, aesthetic, economic value? Compossibility and incompatibility are on a different logical level than desire, approval, and similar psychological phenomena. What is the difference of these levels? How is compossibility as such related to compossibilities of desires? Are there incompatible compossibilities and compossible incompatibilities? How is the compossibility of desires related to the desire for compossibility? And how is the approval of incompatibility related to the incompatibility of approvals? How are approvals related to the various desires? There are as many questions as "explanations"-for the simple reason that here again we have analytic definitions of ignotum per ignotius. It is amazing that a mind so demanding in formal logic can be so easily satisfied in ethics, so content with the mere appearance of coherence produced by random implications of analytic concepts. In 1952, Russell declared himself "not quite satisfied with any view of ethics that I have been able to arrive at, and that is why I have abstained again from writing on the subject." ${ }^{23}$

Thus, Russell's emphasis on reason is somewhat specious. His value properties are emotive properties - his only alternative to their not being sensory properties. Yet, as has been pointed out, ${ }^{24}$ neither are the primary properties of science. Russell does not hold that the first are the emotive ones, but solves what may be called the fundamental relation of science - that between secondary and primary qualities - by his theory of logical constructionism.

John L. McKenney, applying this method to the fundamental axiological relation - that between sensory and value properties-comes to the result that goodness is not a name but a propositional function, a procedure and a result very close to my own. He agrees with me in (1) seeing the analogy between the fundamental scientific and the fundamental axiological relation, (2) asking for an analogous treatment of both, and (3) solving the fundamental scientific relation by the theory of descriptions, thus regarding value as an incomplete symbol, that is, one that has no meaning in isolation; it has a name but obtains its meaning in a context with other symbols. Value thus becomes a propositional function or variable.

McKenney's procedure differs from mine in not clarifying the difference between an analytic and a synthetic context for such symbols. Saying that value may be an incomplete symbol is not sufficient. Necessary also is specifying the context in which it is such a symbol. This context, if axiological analysis is to advance, must not be an analytic one, for example, of psychology or politics, ${ }^{25}$ but must be synthetic. That is, the distinction between concept and term, as developed in The Structure of Value ${ }^{26}$ must be made axiologically clear. Russell himself does not make clear these structural distinctions of the contexts of contextual definitions, due to his empirical view of science. His view of science as a set of incomplete symbols is a halfway house to my theory of science as a formal structure. In using it, McKenney lifted Russell's material view of values as desires into the implicative formality of analytic concepts, but not into the axiomatic one of synthetic terms. ${ }^{27}$ 
A psychological ethics, based on the Gestalt concept, flying, not quite legitimately, the flag of phenomenology, is proposed by Maurice Mandelbaum. ${ }^{28} \mathrm{He}$ approaches the problem of value through a "phenomenological" - "structural," "situational," "contextual" - analysis of moral judgments. Going back to the example of the eighteenth-century British moralists, and in supposed contrast to the linguistic school of Oxford, Mandelbaum examines what he believes to be the facts - as against the language - of moral experience; and he describes the standards he believes to be actually used in value judgments rather than prescribing the standards that ought to be used. He, too, lands firmly on one analytic concept, that of "fittingness," which, supposedly, furnishes the common ground for all moral judgments. This concept is interpreted naturalistically and stripped of some of its eighteenth-century overtones. Mandelbaum believes that the determination of the differentia of the class of moral judgments- "one of the most fundamental tasks of an ethical theory"-is a task of situational rather than of semantic or syntactical analysis. "Any such semantic and syntactical analysis actually presupposes a knowledge of the characteristic of moral judgments, rather than being the means through which such a knowledge can be obtained." 29

Here we have the usual empiristic misunderstanding of the scientific method. As we have seen, the frame of reference - the "syntactical analysis," to use these inadequate terms, the axiomatic construction, to say it more adequately-determines the phenomena of science as the practical part of science itself and the result of its inherent method. Mandelbaum's disagreement with the Oxford School is thus more apparent than real..$^{30}$ It is impossible, he believes, to determine the connotations of terms such as "good," "right," or "ought" without first inquiring upon what occasion and in what different alternative ways these terms are used. He represents, thus, the contextual aspect of the Oxford approach, which is inherently connected with its linguistic aspect. "So long as our aim is that of understanding man's moral experience, an ethical inquiry must constantly cross and recross the boundary between what is asserted by a moral judgment and the psychological aspect of the judgmental act."

"Psychological" is here understood in a kind of Gestalt sense. The trait that all moral judgments have in common is that a direct moral judgment, one made by moral agents in their situations, is always a response to an objective demand, a "reflexive demand"of the situation upon the agent, to complete the situation in just this and no other way. A direct moral judgment is a demand for situational closure in the Gestalt sense of the word. Direct moral judgments are made, and only made, when a situation is apprehended as being somehow incomplete and requiring a certain action by someone to complete it. This fittingness of response is what is meant by "right" and by "good." It is the suitability of an action to a situation, the situation including past and future elements such as promises previously made and purposes and goals to be accomplished..$^{32}$ There is no special non-natural fittingness; moral fittingness is a variety of a generic fittingness that cannot be defined but can be recognized with the help of examples-another affinity with the Oxford position. 
Which of these examples is moral and which not is, of course, the question. Mandelbaum's criteria for the specific moral character of a fittingness - the "externality" or independence of the perceived value with respect to our inclinations and desires, the perception of the value as belonging to a state of affairs that we can bring into existence, and the relevance of this state of affairs to our situation-may apply to any action that fulfills a situation, say an aesthetic one like the completion of a painting. We encounter here the difficulty of any situational and, indeed, empirical approach that attempts truly to analyze the details of moral phenomena: closeness to the phenomenon dulls the sharpness of the analytic instrument. This sharpness resides in systematic definition, which is precluded by the situational and by any empirical approach.

This sharpness is not precluded by a phenomenological approach in the continental sense of this term. Mandelbaum's study does not seem to be such an approach in spite of its title. This title-The Phenomenology of Moral Experience-leads readers to compare the work with accounts such as Nicolai Hartmann's, Strasser's, or Daniel Christoff's, which belong to a different category, namely the strictly phenomenological. To use phenomenological criteria in this sense does less than justice to Mandelbaum's treatise. The phenomenological approach does seem to be able to penetrate to the core of the moral experience, and in such a way as to lead to an axiological systematic. In this respect, Nicolai Hartmann's analysis of the threefold finalistic nexus ${ }^{33}$ is a penetrating and precise account of situational "fittingness," one that seems apt to lead to the very threshold of a synthetic axiological framework and to fulfill the methodological mission of phenomenology: to lead to, or close to, the synthetic essence of the phenomenon.

Following up the analytic implications of traditional philosophical concepts, even in the slightly modernized dress of psychological terminology, is no adequate solution for the ethical problem; nor, for that matter, is it phenomenology in the usual sense of the word. It is not possible to take situational, contextual, or psychological structural categories for categories of Wesensschau. Since the primary requirement of ethical theory at the present time is methodological clarity, phenomenology and situationalism ought to be strictly distinguished. Only in this way can the insights and observations of either be given proper consideration.

In this respect the axiology of Risieri Frondizi ${ }^{34}$ is more straightforward. It steers a firm course between psychology and phenomenology, seeing the locus of value in the concrete situation. Value and valuation cannot be radically distinguished. Neither can be explained merely psychologically, but both are combined in the situational context, where subjective and objective elements form one whole. Among the subjective elements are the past and present psychological life of the agent, the influence of the organism, and the social and natural texture. Among the objective elements are the properties of the thing valued that make it appear valuable independently of the psychological reaction of the valuer. These properties are what other axiologists have called the good-making properties; unfortunately, Frondizi does not give us the details of the relation between them and the value of the thing. The 
fundamental axiological relation remains again in the dark, and the analytic concept "situation," although it gives us a valuable general framework for value, does not furnish us with the tools to penetrate the secret of this relation. However, the situational framework can be logically formalized, and this form would supply these tools. ${ }^{35}$

The culmination of ethical acuteness on a purely psychological basis is reached by A. L. Hilliard, ${ }^{36}$ whose work is the most thoroughly spun out theory based on any particular empirical definition of value. Producing theories as detailed as this based on one particular value aspect may not be in accordance with the law of parsimony, but the fundamental theoretical difficulty appears in the progressive complexity of the work. Still, it brings profound insight into most different value phenomenawhich proves that no matter what theory we select, valuable results cannot fail to appear if only we pursue it far enough and probe it deeply enough.

If "Hedonics" is ever to be, something like Hilliard's work must be its fundamental text. Hilliard does not attempt to argue that his form of hedonics is true. He simply formulates what he understands by it and proceeds within a rigid set of definitions to work out the implications of his formula. As such his is an exemplary work in analytic axiology. The fruitfulness of any value theory, in particular the intuition theory for which Hill "settles," will be demonstrated only by the intensive kind of work Hilliard has undertaken for hedonism. Only that theory will supersede analytic theories thus developed whose elaboration will lead to a synthetic system rather than to an analytic "system," even if ever so acute. Since the development of Moore's theory does lead to a synthetic system, precisely because "good" is analytically indefinable, it is methodologically superior to even as precise an analytic "system" as Hilliard's.

Hilliard's approach is clearly and precisely naturalistic. Values, value propositions, and value judgments are matters of fact, having the same metaphysical, logical, and epistemological status as any other matter of fact. As such, they are open to scientific investigation and control-"scientific" meant in the usual empirical sense. Neither values nor the avenues to value are externally established or prescribed; they are relative to the natures of people and other organisms, their needs, desires, and purposes. The basis of Hilliard's approach is egoistic psychological hedonism.

Against so-called ethical hedonism, which contends that men ought to pursue pleasure as the sole or chief end, although perhaps they do not, psychological hedonism maintains it to be a given fact of human (and for that matter all organic) behavior that pleasure is the sole end pursued; against universalistic or altruistic hedonism, as for instance in most forms of utilitarianism (which asserts that it is primarily the pleasure of others which may and ought to be the end of conduct) egoistic (but not egotistic) hedonism holds that each organism does and can act only to the end of its own pleasure. ${ }^{37}$ 
On this basis Hilliard defines value as affectivity occurring in the relational contexture determined by the reaction of an organism to a stimulus object. ${ }^{38}$ Utility is a character predicable of any object that was, is, or has the potentiality for being an intermediate means for a particular organism. Utility and value have no necessary relation to one another. An object may have utility and not be valued, or it may be valued but not for its utility. ${ }^{39}$ "A spoonful of castor oil may have positive utility for a sick child, but in all probability will simultaneously have negative value-in the child-castor oil contexture there will occur distinctly negative affectivity." ${ }^{" 40}$

Utility is the secondary concept, Hilliard believes, value the primary. Both value and utility may be actual or potential. An object has terminal value when the affectivity determined by a reaction to it is for its own sake, that is, when the object is a last means to the end of affectivity. It has instrumental value when the affectivity determined by a reaction to it is for the sake of some consequent object.

Hilliard distinguishes strictly between intrinsic value and utility versus terminal and instrumental value - between, that is, axiology and teleology. The meaning of the term "good" derives from that of "value," specifically "positive value." "Good" is the general adjective predicable of all those objects that have occasioned, are occasioning, habitually do occasion, or probably will occasion positive affectivity when forming a relational contexture with any organism. Such objects are good for that organism. Just as value is always value for, so good is always good for. ${ }^{41}$

In formal axiology, "good" and "good for" must be strictly distinguished. The identification of the two forms, and thus the disregard of the logical distinction between them, characterizes Hilliard's analytic procedure and that of similar theories, as against the synthetic procedure of formal axiology. It shows up the relativity of this naturalistic kind of goodness. Good is relative and subject to a time reference. That which is good for one organism may be bad for another. No object is good for all organisms, or for any organism at all times.

The adjective "good" is not applicable to the universe, Hilliard believes, since the universe is a whole, and a relation can only exist between parts. Nothing can be said to be good for the universe; whereas the universe maybe said to be good for its beings. Thus, "good for" may be predicated of the universe, but it is not applicable to it. ${ }^{42}$ Hilliard's statement is incorrect according to formal axiology. " $A$ is good for $B$ " means that $A$ and $B$ are in different classes but the intension of $A$ is part of that of $B{ }^{43}$ Accordingly, any being in the universe can be good for the universe, but the universe can be good for a being only insofar as its intension is part of that particular being's intension. This being can be humankind, whose thinking encompasses the universe, and any being whose ontogeny repeats its phylogeny.

Hilliard is as explicit in applied as in general axiology. Aesthetic value is roughly coextensive with terminal or intrinsic value. The work of art is unique, and in a striking way. Take a glass of Burgundy that is enjoyed for its own sake. This "glass of Burgundy" is a complex of elements of experience - certain shades of red, a particular taste, a certain visual form from a certain point of view, coolness, and so on. Hilliard distinguishes 158 elements. All of these, apprehended in any combina- 
tion, may, on any particular occasion, make up the aesthetic object being enjoyed, "a glass of Burgundy," so that there are $2^{158}-1$ or $3.6 \times 10^{46}$ variations of such experience. ${ }^{44}$

Economic value is the instrumental counterpart of aesthetic value, roughly coextensive with instrumental value. It implies a belief in the valued object's utility. Economic utility is a species of the genus utility, the differentia being that the object of which it is predicated is actually or potentially an intermediate means to the production, distribution, or exchange of objects included in the denotation of wealth. Wealth is the class of all those objects that are actual or potential means to value. Hilliard extends this simple formula with amazing ingenuity into a wide ramification of value phenomena and thus fulfills in some peculiar way the task of value theory, as seen by Langmead Casserley.

Ethical value, too, is a form of instrumental value, being an intermediate means to the realization of a last means to positive affectivity. While the species "economic value" of the genus "instrumental value" deals with the object of wealth, ethical value deals with a different sort of object, namely, behavior that affects other individuals in such a manner as to induce behavior on their part, which in turn affects the original behaving organism. They have a socially reflexive aspect that economic values do not usually have. The farmer's ploughing has economic value whether or not any person is affected by it; but insofar as no other person is affected (for example, the farmer self-consumes his crops) the act has no ethical value, either positive or negative. The objects of ethical valuation may have utility. Honesty or courtesy, for example, are objects that, with reference to a particular organism, are useful as intermediate means to more direct means to the organism's satisfaction. Ethical objects are precisely those that possess this socially reflexive kind of utility, and this is the difference between economic and ethical value. Love is finding terminal value in another person rather than in a thing. Truth has both instrumental and terminal value, the first referring to truth about objects- -"truth about"- the second to truth as an aesthetic object of intellectual construction.

The very excellence of Hilliard's work, the utmost care, ingenuity, and precision with which the basic analytic definition is developed, shows up glaringly the shortcomings of the analytic method. In having to take one material aspect of value as Value, such a theory must necessarily disregard an infinite number of value distinctions possible in other theories; and this infinity of disregarded distinctions is not made up for by the distinctions the theory makes, no matter how subtle and ingenious. On the contrary, the very number and subtlety of the distinctions made point up the infinity of distinctions not made, for any other definition of value by an analytic concept could make similar ones, but from this paradox - that the richer an analytic value theory, the more it shows up its poverty as a theory of value. Only a higherlevel value language, a synthetic system, can deliver value theory. All the distinctions possible in material value theories ought to appear as applications of such a system. Consider, for example, how Hilliard glosses over the distinctions between propositions fundamentally so different as "God is good," "So-and-so is a good man," "This 
is a good hammer," "Milk is good for babes," "It is good to avoid parallel fifths in strict counterpoint," "That is not good sportsmanship," "An overdose of sleeping tablets is a good way to commit suicide," "P-QR $\mathrm{QR}_{4}$ is not a good opening move," "I bid you good night," "Cambridge has a good tutorial staff in Greek," "St. Julien is good with a roast, but Pommard is better," "Too much of a good thing," and "Good fences make good neighbors." ${ }^{\text {45 }}$ Axiology ought to define the exact valuational distinctions between these propositions rather than try to erase them.

Missing in Hilliard consciously and on principle is an account of the relations of his system to other systems of axiology. For such an account a formal language of value, a meta-axiology, would be needed. Hilliard does discuss the relation of his axiology to theories of specific values such as ethical, aesthetic, economic, and so on, by defining these specific values in terms of his general definition of value.

Works that deal with, say, ethical value, must in turn define this in terms of some existing axiology. But existing axiologies are material, and to define ethical value in terms of any material term, any satisfaction, does not essentially further the value enterprise. Doing so presupposes an account of the naturalistic fallacy and whether, and in what respect, the theory commits it or not. In this respect Hilliard's theory is not so well founded as other naturalistic theories, for example, G. F. Hourani's. ${ }^{46} \mathrm{~A}$ naturalist of the incisiveness of Hilliard cannot say much more about the naturalistic fallacy than that it fails to establish itself as a fallacy, and this has already been said. ${ }^{47}$ Attempts at refining the fallacy on a level less incisive than Hilliard's and Frankena's are of doubtful value and cannot fail being at least as fallacious as those more incisive attempts. Hourani, for instance, confuses the logic of definitions with the psychology of understanding them. ${ }^{48}$ Frankena's misunderstanding of Moore's fallacy was mentioned in Chapter Four. It may be better not to say anything about the fallacy; for a naturalistic theory to say something about it does not necessarily mean that the theory is methodologically better founded than one that says nothing about it. Hourani's theory, which is on a much less incisive level of analysis than Hilliard's, although it says more about the naturalistic fallacy than Hilliard, may not, after all, be better founded than Hilliard's.

Hourani's theory is of the simpler kind. He merely combines two old standbys, "happiness" and "justice," and defines goodness as "happiness justly distributed." Compare Brand Blanshard's definition combining "satisfaction" with "fulfillment" as discussed in Chapter One. But these are vague analytic concepts. The theory pays the usual homage to the talk of the man in the street-more specifically, "ethical speech in the Western world, more particularly the English-speaking part of it;" but the logical rigor and the axiological results are inadequate in the light of my synthetic norm and of an analytic standard such as Hilliard's. Hourani confuses, for example, goodness with good things and analytic truth with spontaneity of insight. ${ }^{49}$

Hilliard's axiological work uses the method of analytic precision and applies it to a naturalistic content. This will be the case in all naturalistic works that truly realize their program. So far, Hilliard's is the only complete work of this kind, but there are approaches in the same direction: proposals for the application of the 
method of analytic precision-often called "scientific"-to axiological objects conceived as objects of natural science. Here belong essays of Viktor Kraft, F. S. C. Northrop, Anatol Rapoport, Donald Davidson, et al., and Richard Braithwaite.

Viktor Kraft ${ }^{\text {so }}$ attempts a logico-psychological analysis as a foundation for "scientific value theory." He applies logical analysis and empirical examination to value phenomena in order to avoid both undefined absolutism and unlimited subjectivism. As do all cognitivists, he seeks the differentia that all phenomena of valuemoral, aesthetic, economic, and such-have in common. His result is that all value phenomena contain a factual and an axiological element. The second cannot be determined logically, only psychologically; pure value is a logical ultimate that cannot be reduced to another concept. A value judgment contains as a characteristic element an attitude toward an object. Its axiological character lies not in this attitude but in the command to take this attitude. A value judgment characterizes an object with respect to the attitude that is to be taken toward it; the value of an object is a "signal for an attitude." This theory, then, combines in an ingenious manner the normative and the psychological aspects of valuation. Just as Brand Blanshard combined satisfaction and fulfillment, and Hourani combined happiness and justice, so Kraft connects normativity and attitude.

All these are analytic concepts, and any two or more of them can be combined to form a new analytic value theory. We could combine satisfaction, happiness, and normativity or fulfillment, justice, and attitude; in short, $2^{n}-1$ different value theories are possible, where $n$ is the number of concepts like "satisfaction," and "fulfilment" that have at one time or another been identified with value. None of these theories makes any methodological advance, for they are all analytic and hence do not provide a standard for judging among themselves. Only a synthetic axiology can be such a standard. In a formal axiology all such combinations ought to appear in a systematic pattern, as I explained earlier in discussing A. C. Garnett's combination of normativity, reasonableness, and being the object of a favorable attitude. ${ }^{51}$

There is, according to Kraft, no absolute standard to decide which attitudes ought to be taken universally toward any possible object; no standard, thus, makes value judgments universally valid or invalid. Value judgments are factual rather than axiological; they do form a rational system; in so far, logic does serve as a standard for the validity or invalidity of value judgments. Since the factual aspect is always connected with an axiological one, a logical determination is at the same time an axiological one. What it is in detail depends on the exact nature of the connection between the logical and the axiological aspect, and since this is not logically determinable, the exact nature of the connection cannot be either. "In the face of ultimates the clarity and precision ceases with which value judgments can be judged as valid or invalid." ${ }_{2}$ The analytic nature of the theory ends in ultimate vagueness. The rational system of value judgments is merely a hypothetical-deductive one, the axiological contents of which are undetermined; they may be those of egoism or altruism, of humility or superiority, of negation or affirmation of life. Still, one class of value systems has a special claim, namely, those that originate directly with human 
culture. They are the conditions of persons as cultural beings and are in so far universal. What they are in detail depends on the culture in question. Kraft's axiology culminates in a cultural matrix resembling Northrop's.

F. S. C. Northrop's position, developed over several years, ${ }^{53}$ is that values are certain implications and applications of natural science. Simply expressed, moral value, for example, concerns humankind, and human beings are what natural science says they are. Thus, the good for human beings depends on what natural science says. The questions, then, are: What does natural science say, and how does it say it?

Unlike Abraham Edel, Northrop starts at the very core of the scientific method, Galileo's distinction between primary and secondary qualities. He expands this into a distinction between two components of cultural life, the theoretic and the aesthetic. The relation between these components was for Galileo and Newton "three-termed," due to the irreality of secondary qualities. The three terms are, respectively, (1) the material object in the "true, real and mathematical" space and time of the theoretic component, (2) the observer, and (3) the apparent sensed qualities in the apparent relative sensed space and time of the aesthetic component.

For Northrop the relation is two-termed and consists in the correlation of scientific theory (the theoretic component) and empirical observations (the aesthetic component). Not only scientific objects but any object known presupposes this relation, called by him "the epistemic correlation." In the case of everyday objects the theoretic component is a set of Kantian or other categories. Thus, "to be any complete concrete thing is to be not merely an immediately experienced, aesthetically and emotionally felt thing but also to be what hypothetically conceived and experimentally verified theory designates." ${ }^{54}$ This epistemological view has axiological consequences.

As far as moral good is concerned, since human beings and nature appear different depending on the epistemic correlation in different cultures, also the good for persons - and the good person - appear different depending on this same correlation. The idea of good depends on the idea of human being, which depends on the idea of nature, which in turn depends on the epistemic correlation characterizing the particular culture. In a formula, "good for culture" is what is true for nature in that culture. The word "good" is nothing but a name for the set of elementary concepts used to conceptualize and integrate experience. It is not a concept within a person's philosophy; nor is it a concept referring to an inductively given datum in a person's experience. Instead, it is the name for all the other concepts of knowledge when they are considered in their interrelation and unity, not only with respect to natural science and its verifications, but also with respect to their implications for the fulfillment of human nature, when applied to an act of human behavior and to human relations. The class designated by the idea of the good, as Northrop puts it with E. Vernon Arnold, ${ }^{55}$ is "a class which includes all classes." It is the word used to designate the set of basic assumptions used in a person's philosophy. Moral philosophy must be so constructed as to exhibit these basic assumptions, that is, as a deductively formulated theory. 
Any such theory, Northrop holds, has in its postulates all its basic common denominator concepts - the primitive concepts that are taken as undefined and used to define all other concepts in the theory. This set of primitive concepts and postulates is very small. Newton's can be put on one page. The definitions of its eight most important concepts can be put in sixteen lines. Nevertheless, this simple minimum brought under itself the motions of the planets, the falling of bodies, the pendulum, the lever, the balance, the gyroscope, and the rest of the universe.

This method applies to normative theories as well. Needed is

a philosophical articulation of the conception of man and the universe which contemporary empirical knowledge of man and nature entails, and the creation of a new humanism in terms of the new idea of the good which this more adequate scientifically grounded philosophy defines. That conception of good conduct and the good state is the correct one, valid for everybody, which rests upon the conception of man and nature as determined by immediate apprehension (with respect to the aesthetic component) and by the methods of natural science (with respect to the theoretic component). ${ }^{56}$

Following this naturalistic criterion, human beings will learn to know themselves and be true to themselves, for natural science defines human beings for themselves. Ethics must become the application of verified natural philosophy. Ethicists today must become the interpreters of Einstein and Schrödinger, and of their epistemic significance, just as in Newton's time they had to be Newton's interpreters; and ethicists must apply what they have learned to personal behavior and social relations. Ethics must be an art rather than a science, for the science is that of the natural philosophers. All the ethicist has to do is to take over and apply it. Ethics is that natural science thus applied, and natural science thus applied is ethics.

This is, in a grandiose manner, the commission of the metaphysical fallacy. How anachronistic the whole scheme is may be seen from the fact that it is, mutatis mutandis, the same as that of the Greek Fathers and of much of medieval education.

Philosophy was conceived primarily as a philosophia perennis compiled from Platonist, Aristotelian and Stoic sources and divided into physics, ethics and dialectic....Physics was theoretical philosophy, the study of a hypothesis that could account for an ordered and intelligible universe. Ethics was a practical philosophy, the application of this hypothesis to human affairs....For centuries this division was to provide the framework for the speculation of Greek Christian theologians....Their theology is the study of an underlying explanation of an intelligible and ordered nature, their moral theory is its corollary. ${ }^{57}$

To apply this scheme, ethicists must, beside the theoretic component, also know the aesthetic component of human nature. This component is not completely indeter- 
minate; the theoretic component gives it complete differentiation but does contain a differentiation in itself; specific aesthetic qualities vary from person to person and from circumstance to circumstance. In addition to the good that is valid for everybody, the theory also provides for relative goods that do not hold for everybody. It guarantees the richness and variety of life.

Northrop's is a fascinating, rich, and suggestive theory; like Hilliard's, it goes as far as an analytic argument can possibly go. Yet, as an analytic argument it glosses over fundamental logical distinctions; the most essential is that between the synthetic nature of the formal postulates of a science and the analytic nature of the material postulates of a culture. Due to this oversight, Northrop's concept of a "deductively formulated theory" is undefined, and his analogy between the system of science and the "system" of a culture lacks validity in its most fundamental aspect. Rather than stressing the similarity between philosophy and science, he should have stressed their logical difference. In this way, and in this way alone, could he have given valid directions for the scientific reconstruction of moral philosophy. His fundamental concept of "epistemic correlation," is too vague to be scientifically useful; it is an analytic rather than a synthetic concept. Withal, Northrop comes closest to my own point of departure; indeed, his is the same as mine, the difference between primary and secondary properties. His theory fails because he fails to analyze this distinction formally and scientifically rather than analytically and philosophically. In failing to analyze the theoretic component truly theoretically he failed to see the true theoretic importance of the aesthetic component, and he gave this component an importance that is theoretically irrelevant. He also overlooked that his investigation ought to be a theoretic, not an aesthetic, one. He confused the content of his inquiry with its method - the fallacy of method - and blurred his subject matter aesthetically instead of illuminating it theoretically. Galileo's and Newton's method was correct and did not need to be amended to give the aesthetic component its due emphasis; it ought to have been applied to this component. The epistemic correlation is not twofold; neither is it threefold in the Galilean-Newtonian sense; it is fourfold in the sense described above: ${ }^{.8}$ starting with analytic abstractions from sense material, it passes through essential Wesenshau (axiomatic identification), to synthetic construction, and then to an application of the system so constructed to the original material thus newly reconstituted. If Northrop had analyzed the relation in this way his "good" would have coincided with mine and become a logical rather than a natural relation. His theory suffers from the vagueness of an analytic basis. So do its applications.

Northrop applies his theory in many ways; for example, the systematic mediator between the character of the natural and that of the moral laws of a civilization are the juridical laws. Like Hilliard, he fulfills part of Langmead Casserley's program of a humanly relevant theory of value, but the relevance is the inadequate one of analytic concepts, not the adequate one of synthetic concepts. His applications are validly true only if his basic assumption is correct, that human nature is what natural science declares it to be. Should natural science and the epistemic correlation be found irrelevant to our knowledge of our own nature, Northrop's philosophy of value 
would likewise be irrelevant. The synthetic analysis of the epistemic relation leads to the results that natural science is irrelevant to the moral nature of human beings, and that an entirely new science, formal axiology, must be created to account for this nature-a science in which the epistemic relation has other aspects than natural science.

While Northrop sees the essential phenomenon of moral philosophy in the relation between theory and the phenomena it accounts for, Rapoport, Davidson, et $a l$., and Braithwaite see it in one phenomenon, that of choice or preference in human situations. They all apply scientific methods to it: Rapport the operational, Davidson, et al. the axiomatic, and Braithwaite the mathematical method.

Rapoport ${ }^{59}$ proposes an "operational ethic" that rests on the pragmatic premise

that rules of conduct and goals should not be stated a priori but should emerge as the result of the best method of inquiry at one's disposal. Therefore the goals (the 'good,' the 'ultimate ends,' etc.) of this ethics cannot be explicitly stated. ...There is always a possibility that improved methods of inquiry will reveal more desirable goals....Just as there is no absolutely final act in science, so there is no absolutely supreme good in operational ethics. ${ }^{60}$

Values may be postulated like scientific hypotheses. Some of these values may be supported by success in their application, others not. Values are the invariant needs of human beings. Ethics should be an inquiry into what sort of conduct can satisfy these needs most effectively. Operational ethics leans on the sociology of knowledge and modern psychiatric theory. It is an empirico-scientific inquiry. The chronic question, "Can science be applied to ethics?" is answered from the operational point of view by saying that basic invariant human ends are not subject to ethical discussion, which concerns choices, because we have no choice but to pursue them. They can be determined by scientific investigation, just as physiological means are so determined. The method of reducing ethics to science is, then, to reduce the number of ends we are choosing to a minimum. The ultimate invariant ends are the final object of ethics, but in arriving at them ethics ceases to be ethics and becomes natural science. Rapoport, by a twist of the naturalistic argument, arrives at a positivistic conclusion.

\section{Naturalistic Formalists}

While semi-cognitivists are sensitive to the axiological nature of value but lack sensitivity for its cognitive nature, naturalistic empiricists are sensitive to the its cognitive nature but lack sensitivity for the axiological nature of value. The semicognitivists sacrifice intelligibility of value perception to its sociological character; the empiricist cognitivists sacrifice understanding of its axiological character to its intelligibility. In neither case does the value realm become understandable as such. 
The naturalistic formalists advance in the direction of genuine axiological knowledge by a more sophisticated understanding of the nature of cognition. They see that method is, if not more important, at least as important as content. Even though most of them still tie value to some analytic concept, they elaborate this concept in a formal rather than a material and naively implicative manner. Though the "formal" nature of their "systems" is still analytic, tied as it is to the analytic concept in question, their emphasis on method at least begins to point toward a genuine formal system rather than material axiological system.

Donald Davidson, J. C. C. McKinsey, and Patrick Suppes ${ }^{61}$ use an ordering principle opposed to Rapoport's. Instead of whittling down the number of possible ends to avoid contradiction among them, they endeavor to find a universal frame of reference that will account for all kinds of possible preference processes. They follow the axiomatic method of science. Their value theory is a formal one, and, since it is based on a naturalistic phenomenon, that of choice, it is a naturalistic formal one. Choice is for them not a subject matter of natural science itself, as it is for Rapoport, but of a frame of reference suigeneris, produced ad hoc for the purpose at hand. This frame of reference, therefore, is not constructive or synthetic in the sense that it defines its subject matter-choice-autonomously, as do theories in physical science, but abstractive or analytic, elaborating the subject at hand in an axiomatic or, if we reserve the term "axiom" for synthetic systems, a theoretical manner. They do not identify an element of logic with value, defining value synthetically in terms of this element, as Galileo identified an element of mathematics, conic sections, with the path of a projectile and defined this path synthetically in terms of this element. Rather, they define value analytically, as preference, and then apply the logic of relations to preference as a relation. Even if we disregard the analytic definition of value as preference, we do not have here a creative-constructive identification of preference with an element of logic that has never yet been connected with it, but we have the usual application of the logic, fitting the term "preference" to it. We thus have the formal elaboration of an analytic concept. The result is an empirico-formal theory, similar in method to, though far less rich in content than Hilliard's, but it is not an a priori formal theory. Such a formal theory would be non-naturalistic, of the kind to be discussed in the next chapter.

Davidson, et al. take it as the general function of "formal" value theory to provide "formal" criteria for rational decision, choice, and evaluation. Just as logic can be used to define necessary formal conditions for rational belief, so value theory defines "necessary formal" conditions for rational choice. These authors do not sufficiently emphasize the difference between the synthetic formality of a logical system and the analytic "formality" of a material theory to whose analytic concepts formal logic is applied. The events, acts, objects, or goals to which value is attributed are the subject matter of their theory, along with the ordering relations of preference, equivalence in value, and difference in value. Their theory attempts to establish a "rational preference pattern," a pattern of preference that follows the rules of transitive relations, and to discuss the problem of measuring preferences. Of the four 
possible measuring procedures, by (1) absolute scale (applied to the cardinality of classes), (2) ratio scale (mass, length), (3) interval scale (longitude, time), and (4) ordinal scale (Beaufort wind scale), the authors believe preferences to be measurable by the third scale and "rational preference ranking" by the fourth scale. The measurements in question are the weakest of the scales possible; what they measure is value only if value is identified with preference, which means committing the naturalistic fallacy. Formal axiology measures value directly, and by all available scales. ${ }^{62}$

In so far as Davidson's et al. theory is axiomatic, even though theoretico-axiomatic rather than systemico-axiomatic, and because in such an axiomatically formulated theory its primitive and defined notions have a meaning only as part of the theory, their approach would eliminate for value theory the need to depend on the inadequate resources of ordinary language. This would help overcome the frustration that results from an attempt to explicate the basic value concepts in isolation from a coherent theory. But it does not lift value theory to the level of value science, and it does not convert the analytic basis of the theory into a synthetic one. The theory is a kind of naturalistic meliorism. While non-naturalistic meliorism is based on the synthetic relation of bitterness, naturalistic meliorism is based on the analytic relation of preference. On its three logical forms, $X$ is preferred to $Y, Y$ is preferred to $X, X$ is equal in preference to $Y$, patterns of preference can be constructed which, by using probability considerations, may be built to higher and higher complexity. The value of such a theory, if fully developed, would be the same as that of Hilliard's: its very complexity and ingenuity would show up its axiological insufficiency.

The reason is the "intrasystematic arbitrariness" discussed above in Chapter Two, Section 2, C. As a result, the "logic of preference" may lead to various kinds of interpretations, the axiological nature of which is doubtful. In the case of Davidson and Suppes ${ }^{63}$ the outcome is an experimental approach to decision making.

In the case of G. $\mathrm{H}$. von Wright ${ }^{64}$ we have what he calls an axiological treatise considered as a part of the "logic of value." In the course of his "axiomatic"65 approach, von Wright defines "good" and "bad" in terms of preference ${ }^{66}$ and reaches, among others, the result that "good is better than bad,"67 a result which he rightly says is no "mere triviality." Von Wright's definitions of "good" and "bad" may be called exact naturalistic translations of the non-naturalistic definitions of Edwin T. Mitchell. Sören Halldén's On the Logic of "Better" seems to be a non-naturalistic meliorism like that of von Wright, but the "philosophical analysis" of the B-relation in Halldén's Emotive Propositions is naturalistic. ${ }^{68}$

If von Wright's conclusion, among others, that "good is better than bad" had been reached by non-naturalistic meliorism, it would be difficult to say why the procedure is wrong and why "better" ought to be derived from "good" rather than "good" from "better." At least, an axiological fallacy would not be involved. The decision would either have to be made on the basis of the considerations in Chapter Two above, or on the facility or difficulty with which the two axiologies could be converted the one into the other, or the result of the mutual application of the one to the other, in particular the application of the criteria for betterness contained in either 
of the axiologies to the other.$^{69}$ If the results were inconclusive, that is, one axiology is as good as the other and neither is better than the other in their own terms, then recourse would have to be taken to what Bertrand Russell calls "logical common sense," ${ }^{, 70}$ which comes down to the psychologico-aesthetic criterion of Gestalt closure and Prägnanz. ${ }^{71}$ In this case, differences of opinion may prevail for a long time, as was the case in the Ptolemaic-Copernican controversy.

But when it is a matter of a naturalistic melioristic theory, that is, one of preference rather than of logically defined betterness, the situation seems very much clearer, both theoretically and practically. Theoretically, that is, methodologically, the interpretation of the logical truth that $A$ is better than $B$-defined, say, by " $A$ has more of the class properties than $B$ "- as the empirical act of preferring $A$ to $B$, is the same as the Umdeutung of the logical truth that $4>3$ is the stating that this is so. It is an Umdeutung of syntactics into pragmatics. To hold that $4>3$ because it is stated to be, or because a stick of 4 meters length is held to be larger than one of 3 meters, is a reversal of the methodological relation between explicans and explicandum, between variable and range, between number and numeral, which constitutes the fallacy of method. As William Wollaston made clear, an act is right or wrong because of the true or false proposition it affirms or denies, not vice versa, or by itself alone. ${ }^{72}$

This methodological reversal is G. H. von Wright's procedure. His logic of preference does not deal with what he calls extrinsic preference, that is, that kind of preference which has its ground or reason in a judgment of betterness,${ }^{73}$ but on what he calls intrinsic preference, which is preference for no reason except that what is preferred is liked. This kind of preference is constitutive of betterness and "a form of betterness." Preference is undefined; it is merely an act; but in a developed axiology, both kinds of preference in von Wright's sense, extrinsic ${ }^{74}$ and intrinsic, ${ }^{75}$ must be defined. For von Wright, the "logic of preference" is the combination of possible such acts by handling the relation of preference between two states of affairs $p$ and $q$, for example, $p P q$, (the state $p$ is preferred to the state $q$ ) axiomatically ${ }^{76}$ in accordance with the Propositional Calculus. Moreover, the preferences in question are unconditional, which means that "any given state of the world, which contains $p$ but not $q$, is preferred to a total state of the world, which differs from the first in that it contains $q$ but not $p$, but otherwise is identical with it." 77

The theory is of limited applicability, and it is clear, practically, that it cannot be used to decide, for example, why it should be preferred to a formal axiology in which "better" is defined in terms of "good," and preference in terms of "better," nor, vice versa, why the second theory should be preferred to the first. It contains no norms for preference and no norms for comparison. If we inquire into the nature of norms in the sense offered by von Wright in Norm and Action: A Logical Enquiry and Varieties of Goodness,${ }^{78}$ we are forced into the discussion of the relation between "good" and "ought," as is given below in Chapter Eight, Section 2.

Von Wright leaves us with a calculus for a limited kind of acts meaning "roughly the same as what, in ordinary language, we mean by 'to like better (more).' An (intrinsic) preference, one could say with the Oxford Dictionary, is the 'liking of 
one thing more than another."'79 And de gustibus non est disputandum -at least not in von Wright's logic of preference (as against a formal axiology, an estimativa, in the sense of Ortega y Gasset).

Thus, the formula apparatus is based on too thin a base, and this base is at bottom an analytic concept, the kind of concept appropriate for philosophy but not for science, mathematics, or logic - that of "liking." To erect on this base a synthetic apparatus is a procedure that is illegitimate. Withal, von Wright's logic of preference is a significant advance into the largely uncharted realm of the logic of value. It would be an easy thing to strip von Wright's calculus of its "philosophical explanations," in the sense of Sören Halldén, and incorporate it in a truly formal axiology. As for the coincidence of some of its definitions and results with those of non-naturalistic systems, Mitchell's meliorism and formal axiology itself demonstrate that once the logical apparatus is applied, even arbitrarily in the sense defined, to a narrow methodological basis, significant results are bound to appear that show up the intrinsically logical nature of the value field.

While von Wright applies the propositional calculus, and Davidson, et al. apply statistical considerations to value problems, Richard D. Braithwaite ${ }^{80}$ applies value considerations to statistical problems. He believes that such considerations determine to some extent the choice between statistical hypotheses, and that the ethical "irrupts" into inductive logic. He applies probability calculations to the problem of choice and preference. ${ }^{81}$ His example is a situation of two neighbors, Matthew and Luke, one a jazz trumpeter the other a classical pianist, whose performances are a source of mutual discord. He shows with the help of game theory how arbitration between the two is possible. If they are not prepared to co-operate, the most sensible non-competitive and the most prudent competitive course for each of them can be worked out; if they are prepared to cooperate, the theory provides the fairest solution for them both.

The argument rests on the idea that the logic of a general collaboration situation is isomorphic with the geometry of a parabola. This geometry is an envelope of lines (a line parabola or parabola-scroll), uniquely determined by the four pure strategies available to the collaborators, namely, for Luke to play alone, for Matthew to play alone, for neither to play, or for both to play. The importance of the parabola arises from the fact that it has a definite direction, that of its axis; this direction, which is not arbitrary since it arises naturally out of the intrinsic logic of the situation, gives a method of comparing the preference scales of the two collaborators. "And if this can be done, it will be possible to measure (by the probability-combination-indifference method) the relative advantage Luke has over Matthew, or Matthew over Luke, for the different possible outcomes." ${ }^{22}$ Braithwaite calculates that the fair decision would be to award to Luke 17 out of 43 evenings and to Matthew 26.

Thus, in any two-party dispute, where the ratios of preferences can be determined, the theory of games can dispense exact justice. This gives the axiologist the role of an arbiter similar to that of a judge. If Luke and Matthew should come to consult Braithwaite as to how they should act in their specific situation, the procedure 
would be as follows. He would first tell them that he could not give them any advice unless they provide him with the relevant data, giving sufficient information about their preference for the alternative possible outcomes of their eventual collaboration, and for probability combinations of these alternative outcomes, to enable him to measure each of their preference scales separately. He would then do "some simple mathematical calculations," as a result of which he would make the specific recommendation mentioned, explaining in detail his reasons and hoping that "the sweet reasonableness of [his] parabolas" would convince them. This procedure, Braithwaite believes, would be giving an "explication" or "rational reconstruction" of the concept sensible-prudent-and-fair in collaboration situations, which up to now has been used loosely by common sense, and which is now being tightened up by a precise method. He feels he would make "a small contribution toward realizing Condorcet's dream éclairer les Sciences morales et politiques par le flambeau de l'Algèbre." ${ }^{33}$

Here we have a significant advance in the direction of scientific, that is, synthetic cognition of value phenomena. Braithwaite's method is truly scientific in the sense defined: he discovers an isomorphism between a value situation and an element of a formal pattern that has not been seen before which makes synthetically precise previously analytic concepts such as "sensible," "prudent," and "fair." He constructs a truly axiomatic system and applies this system to the situation for which it was invented. Unfortunately, this situation is not the situation of value but that of a particular value, choice; hence, the synthetic procedure is too limited to serve as the basis for a general formal axiology. Yet, in such an axiology Braithwaite's pattern ought to find a place, just as N. Oresme's pattern found a place in Galileo's general theory of motion ${ }^{84}$ and Galileo's own pattern a place in Newton's general theory of gravitation. ${ }^{85}$ Observe that the mathematical origins of natural science in the middle ages referred to intensions rather than extensions, to qualities rather than quantities.

The largest advance possible on the side of naturalism in the direction of synthetic knowledge of value would be the proposal not to use any content of a science nor any content of a value theory but to apply the mere method of science to value in general. But this would transcend the framework of naturalism and be a non-naturalistic formal theory. The farthest advance in this direction possible within naturalism would be the proposal to apply the mere method of science to a valuational content. Such a content would still be naturalistic in the sense of not being Value itself, but it would not be naturalistic in the sense of being an object of natural science, as is Rapoport's "choice"; it would be an object of axiology, as is Braithwaite's "choice." But it would not be the object of Axiology, Value itself. It would be "naturalistic" in the formal sense but not naturalistic in the material sense. Unfortunately, these two senses of the word, contained in Moore's "naturalistic fallacy," have never been clearly distinguished. "Pleasure" is a value term, but it is not the term "Value." To identify it with Value is a confusion of species and genus. "Evolution," is a factual, not a valuational term; to confuse it with Value is a metabasis en alto genos, a confusion of two genera. The first is the formal confusion and the second 
the material confusion contained in Moore's "naturalistic fallacy." Both are moral fallacies in my sense, but the second is, in addition, the metaphysical fallacy.

The farthest advance possible within naturalism toward formal knowledge of value is formal naturalism, or naturalistic formalism, in the widest sense: the form in question being the scientific method itself, not a specific section of it as in Braithwaite and similar writers. ${ }^{86}$ I will discuss views of this nature in a scale of decreasing precision of the "scientific" method proposed.

Most precise in his demand for a value science along the lines of natural science method, but not natural science content, is Henry Margenau. Two earlier articles of Margenau, "Scientific Ethics" and "Remarks on Ethical Science"87 are clearer than his Ethics and Science, ${ }^{88}$ which is based, from my point of view, on committing the fallacy of method, in particular the normative fallacy - the postulates of ethics are supposed to be imperatives, and these are supposed to correspond to the postulates of science, like Newton's law of gravitation-precisely the fallacy against which Einstein warned.

As explained in Chapter Two, ethics is a language that analyzes moral experience, but it does not moralize. The imperative is not part of ethics; it is part of moral experience. It belongs to moral, not to ethical language. Ethics deals with moral imperatives; it does not enounce them. Those who enounce them-Confucius, Buddha, St. Paul, Luther-are preceptors of the experience, prototypes to be followed, and as such objects of Ethics - even though, in a different role, they may also be ethicists. But the "imperative" of the system of Ethics is not that with which it deals. Its "imperative" or "obligatory" nature arises, like that of any science, by the synthetic a priori necessity in virtue of which it is a system.

The result of these confusions of levels of value discourse is that a number of vital distinctions are not as clearly made as they might have been, such as those between imperative and norm, formal and material norm, ${ }^{89}$ value and goal, knowledge and method (analytic and synthetic method), and ethics and axiology; and the difference between secondary and primary qualities is taken as a material rather than a formal one. All this obscures the basic soundness of the approach. Moreover, there is a certain unfamiliarity with ethical theory and its terminology, for example, the use of the words "natural" and "necessity" (the first being identified with "natural" in "natural science," the second with normativity), ${ }^{90}$ so that the greatest advance in ethical theory, Moore's distinction of natural and non-natural properties, is regarded as one of the features that show ethical discussion as "descended to the lowest intellectual levels in philosophical debate." Fil Finally, Ethics and Science drops the discussion of the relation between axiology and ethics, not because the author does not hold it any more but, as Professor Margenau told me, because it is obvious. Thus, although the parallelism between axiom and postulates and between verification and validation is ingenious, it lacks a foundation and hence gives rise to the fallacies mentioned. For these reasons I prefer to discuss the first-named writings, where the author's basic approach appears in pristine clarity. 
If ethics and, in general, value theory have a methodology at all, it must be similar to that of natural science, for this is the only method of precise knowledge we have. Yet, it is impossible to deduce by logical sequence the norms of any ethics from the contents of a science. Only the primary structure of science can manifest itself in ethics, and it should do so if that discipline is to partake of the vitality and self-corrective power of true science. By "science" Margenau understands, as I do, exact or deductive science, restricting his considerations to disciplines that have a mathematical or logical structure.

Logically, deductive science has three phases: the postulational, the explicatory, and the verifying. Postulates are human creations that are valid if experience justifies their consequences. Scientific postulates are norms of thought which, when fully formulated and clearly understood, are accepted for methodological purposes as true and consistently adhered to with utmost care in all deductive procedures. Having clearly formulated its basic principles, science is needed to appraise them, to select the worthy from the base. We may even go further and claim that norms can be the generators of new values, just as new theories may call for new observations. It seems clear that all approaches that narrowly seek out existing values and try to reach inductively from them a moral code are futile. Norms of ethics, according to this view, should be respected without exception, as are theories in science. Their validity should be absolute even though, like scientific axioms, they would change in time.

Henry Margenau's is a suggestive program for a scientific ethics, but it does not emphasize sufficiently the difference between inductive generalization and deductive systematization. This is remedied in his Ethics and Science where the discussion of axiology is dropped; so his argument still suffers from insufficiency. This difference is all-important in value theory today, and in this respect a simplistic analogy between the method of today's science and axiology breaks down. The analogy must be between the origins of natural science and axiology. Today science is "playing both ends against the middle"; it can afford to do so because Galileo established the empirico-deductive frame, and hence the rules of the game. But, as previously explained, it makes all the difference in the world whether a science is to be newly established and its frame of reference creatively determined, or whether refinements take place within an established frame. There was a difference in kind between Aristotle and Galileo, but only one in degree between Galileo and Newton (or Newton and Einstein).

Axiology today must take the step from Aristotle to Galileo; hence, the debate in ethics and value theory cannot be the same as in science. Axiology cannot yet play both ends - the practical and the theoretical, the inductive and the deductive, the material and the formal, the analytic and the synthetic - against the middle because one end, the theoretical (deductive, formal, synthetic) is still missing. Only when it is supplied, as is done in formal axiology, can the scientific game in the sense of Margenau be played. Until then, there is no axiological science, but only axiologlcal philosophy - practical, inductive, material, and analytic, as was alchemy. Not to see this clearly ensnares us in fallacies. Margenau confuses analytic ethical principles, 
such as the Ten Commandments or the Golden Rule, with synthetic axiological principles. Only the second, but not the first, can serve as axioms for the science of value. For a similar endeavor and a similar failure, see Jacques Rueff. ${ }^{92}$

In spite of all this, Margenau's view is in the great tradition of natural-moral philosophy, from Plato to the rationalists, to Immanuel Kant, Ernst Cassirer, and Albert Einstein. That this view lost its verve in the subtleties of G. E. Moore is not due to lack of intellectual penetration but, on the contrary, due to it. Moore refined ethical language to such a point that the next step, as John Maynard Keynes observed, ${ }^{93}$ could only be mathematical, the science of value. Unlikely as the combination would appear to both, Moore and Margenau echo the voices of the great rationalist tradition - as does any scientist in our time, such as Einstein.

Descartes, Leibniz, Spinoza, Hume, even Berkeley, shared this tradition: for them, there is no difference in the rationality of natural and of moral philosophy. Leibniz, in particular, had exactly the same vision as the one here under discussion and came to the same results concerning a science of value. The mathematical method is only a specific kind of a general logical method that could be applicable to ethics, metaphysics, and the rest of the humanities, as mathematics is to natural science. Arithmetic and algebra only give us a glimpse of that general method. "It is as if God, when he bestowed these two sciences on mankind, wanted us to realize that our understanding conceals a far deeper secret, of which these are but the shadows." ${ }^{\prime 4}$ It is the secret of a "true method," a universal logical calculus, applicable to morals as well as to nature, which is

a thing hitherto quite unknown, and has not been practiced except in mathematics.... If those who have cultivated the other sciences had imitated the mathematicians, at least on this point, we should be quite content, and we should have long since had a secure metaphysics, as well as an ethics. ${ }^{95}$

The logic Leibniz had in mind and partly developed is the kind of intensional logic that serves as basis of formal axiology. ${ }^{96}$ Leibniz, at the beginning of natural science, saw more clearly than Margenau and even, in a way, than Einstein at the present culmination of natural science, what is implied in the formal nature of ethics as an axiological science: that its postulates must not be empirically taken from its body of existing rules - such as the Ten Commandments, the Golden Rule, the preservation of life, and the like - as both Margenau ${ }^{97}$ and Einstein ${ }^{98}$ believe; but that they must be deductively arrived at by applying a formal system to the specific subject matter of ethics, in exactly the same way that the postulates of physical or any other natural science are arrived at by applying mathematics to the specific subject matter of that science. The crucial problem of ethics is the derivation of its postulates from a formal superstructure, and hence the creation of this superstructure.

Albert Einstein saw well the nature of the problem, even though he did not see clearly its solution, which lies in the formal analogy between moral and natural science. 
What is the origin of such ethical axioms? Are they arbitrary? Are they based on mere authority? Do they stem from experiences of men, and are they conditioned indirectly by such experiences? For pure logic all axioms are arbitrary, including the axioms of ethics.99

But, as we saw in Einstein's account of the scientific method, the arbitrariness of axioms is only apparent. Liberty of choice here is of a very special kind; it is not that of the fiction writer, but that of the puzzler who hits upon the "one word which really solves the puzzle in all its forms."

This one word in ethics is that spoken by G. E. Moore, in my reinterpretation. Whether it really is the true word is a matter to be decided by the practical efficiency and efficacy of the ensuing theory. For, say both Einstein and Margenau, "ethical axioms are found and tested not very differently from the axioms of science. Truth is what stands the test of experience." 101 The meaning of truth in ethical theory must be the same as in scientific theory, namely, corresponding to the three levels of science: (a) the inherent consistency of the system, (b) its applicability to the phenomena that are the subject matter of the science, and (c) the faithful agreement of the results of this application with actual experience. In terms of the science of ethics, this means that ethical (and moral) truth consists in (a) the inherent consistency of the system of formal axiology, (b) its applicability to ethical (and moral) phenomena, and (c) the faithful agreement of the results of this application with our ethical (and moral) experience.

The difference between "ethical" and "moral" refers here to the two levels of ethical science discussed earlier as the double function of metaethics: the negative of criticizing traditional ethics, and the positive of constructing a framework for moral experience itself. The truth of ethical science is the applicability of this science, as a coherent formal structure, to ethical phenomena, namely existing ethical theories, and to moral phenomena, namely moral situations, and the faithful agreement of the results of these applications to our ethical and moral experience, that is, to our study of ethics texts and our actions and affections in moral situations. Such an agreement constitutes a value, just as an agreement between natural science theory and application constitutes a fact. ${ }^{102}$ The totality of these first agreements makes the world of values; the totality of the second agreements makes the world of facts. No scientist makes these exact analogies, and none but Margenau develops at all in detail the relation between science and ethics.

Some mathematical scientists such as J. Bronowski, ${ }^{103}$ Abraham H. Maslow, ${ }^{104}$ and Lillian R. Lieber ${ }^{105}$ attempt to derive morals from mathematics and science as an activity - that is, values from valuing, as the scientist does. This is again the fallacy of method as found, in a different way, in Margenau. Here the scientist is taken as the prototype of the moral man, as in Margenau the prophet. The scientist in this view, is moral, but ethics is not moralizing. It presupposes thinking about morality, not being moral. The programs in question are petitiones principii. 
While Margenau gives explicit specifications for a scientific axiology which is yet not natural science, D. Daiches Raphael ${ }^{106}$ gives the outline of such an axiology, or at least such an ethics. He is concerned with two problems: first, to find a common criterion for all right action, or the relation between the right and the good, second, to discover the nature of moral judgment. The first he calls a problem in the logic of morals, and the second a problem in the metaphysics of morals.

The logic of morals is concerned with the system exhibited or implied by moral judgments. It has to examine the logical relationships to each other of moral concepts (for example, whether goodness implies obligation, or vice versa) and with general moral principles (for example, the principle of obligation), and to find out if the system of interlocking principles thus constituted can be shown in a hierarchy of dependence. In short, the business of the logic of morals is to show the logical structure of a moral system (or of ethical language). Its primary data are the moral judgments made in ordinary life. The logic of morals has the task of making explicit what is barely implicit in these judgments and of clarifying and refining the relationships between moral propositions. The method of doing so is that of all systematization: seeking out general principles, and rendering these principles consistent both with each other and with the particular facts that they claim to cover. The first kind of consistency is the coherence of the system of general propositions. The second is accordance with the particular facts or data to which the system applies - in the case of ethics, the particular moral judgments of common sense made in concrete situations. The system in question is an abstract logical schema that must satisfy the requirements of a deductive system and at the same time be applicable to the set of facts that it claims to systematize. The situation is exactly the same as in an empirical science, that is, the application of a logical system to a set of facts.

Raphael formulates on the side of moral philosophy the same task for ethics as Margenau on the side of nature philosophy. By metaphysics of morals he means an examination of the relations of moral judgment to other systems of concepts and to the facts of experience.

Raphael executes his program by suggesting that "ought" and "good" should be taken as the two basic concepts of the system and asking whether either of these can be eliminated, so that the logic of moral concepts could be based on a single concept. His result is that one sense of "ought" (or "right") is definable in non-ethical terms, or in a combination of non-ethical terms and "good," while another sense of "ought" is not so definable. One ethical sense of "good," namely moral goodness, may be translated in terms of the moral "ought" (and perhaps of deserving, which itself requires consideration); another ethical sense of "good," namely intrinsic good other than moral good, is not so translatable.

Raphael has therefore eliminated from his basic concepts of the ethical system certain senses of the words "ought" and "good," but he is still left with two independent ethical notions, the idea of moral or "categorical" obligation, and the idea of nonmoral, intrinsic good. Following A. C. Ewing, ${ }^{107}$ he then replaces the concept of "good" with that of "fittingness," defining " $\mathrm{X}$ is good" as " $\mathrm{X}$ is a fitting object of a 
favourable attitude" and "X is bad" as " $\mathrm{X}$ is a fitting object of an unfavourable attitude" (including prevention and removal).

The relation between goodness and obligation, then, is that fittingness is, in certain circumstances, "a half-way house to obligation." But this relationship belongs to the metaphysics of morals; within the logic of morals both concepts have different meanings and are independent of each other. The fundamental notion of obligation-and this is the subject matter of the metaphysics of morals-is the Kantian principle: treat persons as ends, of which all other principles of obligation are determinate forms. The idea of moral obligation arises from an imaginative joining of personalities, an inter-personal relation of thinking of another's interests as if they were our own. This principle is a postulate that seems to work like a category of action. It unifies systematically all principles of obligation. Even if it is unacceptable, says Raphael, the fact remains that some moral principles have implicative relations with each other that flow from their ethical as well as from their non-ethical terms. This, he believes, is in itself sufficient to justify the view that moral judgment includes a priori thinking.

To say that moral judgments are rational is simply to recognize the possibility of a logic of morals. It does not prove anything about the facts to which moral judgments refer, but merely points out that moral judgments imply universal propositions and concepts with logical relations between them. ${ }^{108}$

Empiricist theories of moral judgment deal with quite a different matter, the relation of ethical language or concepts to experience. They presuppose a particular theory of reality and attempt to account for the rise of moral concepts from what they take to be real. Too often empiricists have confused what they are doing-which is the metaphysics of morals - with an account of the logic of morals.

Although Raphael's system is not a formal logical system - the difference being, as he points out himself, that the logic of morals, unlike formal logic, takes account of the content of concepts and judgments, and not merely of empty forms, and thus is an application of formal logic to a specific field of thought rather than being a formal logic itself - it is one of the few attempts to apply logical structure to moral philosophy. Moreover, it is one of the very few examples in ethics of a writer's being conscious, at least to some degree, of the difference between a true synthetic system and an analytic "system."

Raphael's "system" is analytic, as are many others, for example, Leonard Nelson's; but Nelson continuously confuses the two notions of system. His "systematic rigor" is strictly implicative and philosophical rather than deductive and scientific in my sense of the word. ${ }^{109}$ Raphael takes certain analytic concepts- "obligation," "fittingness," "end"- and puts them into a logical order by concatenating, in as coherent and plausible a way as possible, their implications. He does not apply formal axio-logic to moral phenomena, but he uses ordinary logic for ordinary arguments with material abstractions - the concepts mentioned. He thus develops into a philo- 
sophical system - but not into a scientific system ${ }^{110}$-analytic concepts of the kind suggested by Margenau, and equally erroneously if the axiom is the foundation of scientific ethics. Raphael's system is not synthetic, based on logical construction, but analytic, based on axiological abstraction. Its fundamental notions are naturalistic, at least as far "fittingness" is concerned, which is a matter of "attitudes," but also, perhaps, insofar as the basis of obligation is concerned, which is a matter of sympathy. These notions are not really treated as subjects of natural science, but of a system sui generis. Though somewhat like Kantian categories in their implicative power, these notions are yet not such categories, partly because Raphael does not construct them as such, and partly because they lack the systematic import that the Kantian categories derive from their logical deduction. In Raphael, the logic of morals has no explicit connection with logic.

The same goes for other attempts in the same direction, such as David John McCracken's, Hellmuth Stofer's, and Paul Kecskemeti's. For McCracken ${ }^{111}$ value is explicitly a category of the understanding analogous to the Kantian category of causality. In reflective valuing our intellects are determined by their nature to formulate value judgments. We can say a priori of every human situation that the valuecategory is applicable to it. For example, we can say a priori of every sensory field that it has some aesthetic value, or of every situation in which we have to deal face to face with another person that it will present us with a scale of significant alternatives and a choice in terms of values. This does not mean that value judgments (for example, "The Nazi's treatment of the Jews was evil") are "a priori true" or are "synthetic a priori," but only that they are a summing up of a situation in terms of the value-category in such a way as to make its relation to me as judge and agent and to other judges and agents more intelligible. Such a judgment is true in the sense that

if I could not assert it as valid not only for myself but also for others, my world would be less 'intelligible'-intelligibility being here taken to involve a relationship not only to my 'pure' thinking, but to by purposes as well. If I wanted merely to say that I dislike the infliction of suffering on racial grounds, I should say so. When instead I make the assertion ' $x$ is evil,' I am making a predication in terms of the value-category which by its very form claims objectivity, claims to hold for others also, and is deliberately chosen to express this claim. It is true that the ethical disvaluation of cruelty is attended by feelings of 'dislike' and impulses to arouse similar feelings in others; it is also attended by factual judgments like: 'This situation is of the same type as others punished by law'; but neither such feelings nor such facts exhaust the meaning of the ethical judgment or even constitute its central core. Its predicate, in so far as ethical, is irreducible to non-ethical terms. ${ }^{112}$

Hence, the proposition " $x$ is red" is only grammatically similar to the proposition " $x$ is good." The difference does not lie in the fact that "good" is a merely emotive predicate, while red is a simple quality "given" to sense. The difference is that when 
I say " $x$ is good," I characterize the whole situation in which $x$ occurs, including its relation to me and to other agents or spectators, actual and potential; " $x$ is good" is shorthand for a detailed description of a total differentiated system of relations.

To call an action, for example, 'good,' is to indicate that it is so related to a context of things and persons that the total pattern calls forth or demands the application to it of the value-category, in the special sense that has come to be called moral; and (in the case of 'goodness') with a special 'pro' emphasis. The 'pro' emphasis recognizes a positive claim upon emotion, will, and intellect, and commits one to an appropriate active response as occasion arises. ${ }^{113}$

While epistemologically speaking, "value" is an a priori category, objectively or in the "material language," value is a structural property of total situations. It is a complex relational property, and to seek any of the traditional trinity of termsBeauty, Truth, and Goodness - as a "simple quality" is "a fool's errand." The concept of value is not a class-concept derived inductively from particular experiences, but a category of the understanding.

McCracken makes the best of this suggestion. Much of the history of the category of cause is comparable to the present state of the category of value, especially its supposed indefinability.

If the idea of value can be taken as a category of intelligibility, in analogy with the factual category of cause, then theories of value may be contributions to knowledge no less truly than theories of physical causation; and the conception of knowledge can be taken as having the wider meaning which is very properly ascribed to it in ordinary speech, that of having as its aim not mere description of actual connections, but the comprehension of the data of experience as intelligible. ${ }^{14}$

We have here advanced a further step in the cognitive understanding of value. Obviously, if value were a Kantian category like the fundamental scientific category of "cause," then a science of value would only be a matter of time. Unfortunately, Kantian categories do not make science, even though up to a point they explain it. What makes science is a formal structure applicable to the phenomena in question. Yet, Kantian categories go far in making a science out of epistemology, for they do contain a formal structure, due to the deduction of the categories from formal logic. "Value" as a Kantian category, although it would not create a science of value, could yet create a science of valuational epistemology; and insofar as the knowledge of the knowledge of value were a science of value, it could create such a science. But this would be the case only if value were indeed a Kantian category, that is, one constructed synthetically on the basis of a deduction from a formal system (in Kant's case, logic). Unfortunately, this essential prerequisite of a Kantian category - which makes these categories both universal and precise-is missing in McCracken's 
account. His is, again, an analytic and implicative, rather than a synthetic and constructive account. If value is to have a categorial nature, this nature must not simply be stated, it must be deduced from logic or some other system, which will give it systematic import.

The same systematic shortcoming we find in similar cognitive approaches to valuation. The unknown nature of value overwhelms even deeply cognitive approaches with its own obscurity. For Hellmuth Stofer, ${ }^{115}$ too, valuation is a categorial function of human beings. Just as cognition contains a variety of ordering categories, such as space and time that make it possible to delimit and comprehend objects, so valuation depends on a variety of experiential factors that alone make possible a selection among possible modes of reaction. If all sensible qualities were of one and the same kind, a differentiation of objects would be impossible; all feelings of pleasure or pain would be of the same kind and intensity.

Stofer distinguishes between logical, perceptual, and value judgments and determines the correctness of each such judgment. Logical judgments are correct either because they are consistent within a system or, if judging the correctness of the system itself, if they are useful for definite cognition. Perceptual judgments are correct insofar as the perception is useful for definite purposes. Whereas a perceptual judgment and a logical judgment are limited to the cognition of processes and objects and realize the connection of representation in accordance with simple thought operations, a value judgment, in addition, contains psychical acts that are founded in the contents of perception or other contents of consciousness; but it transcends these and represents an entirely different kind of reality, namely, values.

The value function makes possible a purposeful action or reaction of the recognizing subject for itself and other subjects. Value judgments are correct if they offer to subjects the motives of their action necessary for their choice. The foundation of moral valuation is sensitivity, based in feeling and perception, possessed by people in various degrees, forming subjective hierarchies. The object of ethical valuation is human conduct insofar as it is willed and its consequences can be surveyed. Stofer's value theory is ultimately based on the quasi-psychological empirical concept of choice. It is not, and cannot be, more precise than this concept.

Paul Kecskemeti ${ }^{116}$ attempts another rational account of valuation on the basis of moral disagreement, not as exact as Braithwaite's, but by a kind of categorial approach. His category is that of "impartiality." Arguments about autonomous values are neither about facts nor about the logical consequences flowing from axioms or assumptions; yet, they are not unstructured. In all of them it is possible to distinguish "postulational" and factual components. Kecskemeti agrees with Charles L. Steven$\operatorname{son}^{117}$ in breaking down value judgments into a postulational and a factual part, and he also agrees that agreement is possible only if a common postulational ground exists. But the postulational component cannot be simply equated with "demands," "imperatives," or "desires."

The "postulates" on which the disputants may or may not agree are standards of a conflict level higher than one, that is, the level on which "desires" may conflict 
with "facts." The judgment, "This is right," means more than the statement, "I wish people would act this way." It presupposes a standard on the basis of which people may distinguish right from wrong, regardless of all momentary demands or interests. Agreement is possible only if all disputants have such a standard in common. If some ethical standards are autonomous rather than hetoronomous, then ethical discussion may in some cases parallel the one about scientific fact finding; it may appeal to a "rational" standard rather than to an irrational one. This autonomous standard is, precisely, the principle of impartiality. It defines the meaning of a social situation, namely that in which the participants agree that the correct decision concerning the matter under dispute must be invariant with respect to their personal interests or demands.

The principle of impartiality is, logically speaking, a postulate. It is neither an analytically true formula nor a statement of fact. Hence, in a sense everybody is free to accept or to reject it; but it is not irrational. It is rational in the same way and for the same reason that the basic postulates of scientific activity are. These postulates, as value standards, are not "rational" because they are logically or empirically demonstrable; their rationality consists in their capacity to generate consensus in a social situation without recourse to suggestion and coercion. The same is true of the principle of impartiality, although to a lesser degree. To the extent that the disputants can "see the point" of a free, impartial ordering of society, they also work toward a consensus that is not based on either coercion or suggestion. The difference is merely that, in the case of ethical principles, shaping actual decisions according to the standard is a matter of approximating an ideal in a more or less imperfect way, whereas in science exact measurements make possible reaching the standard in every case.

Here we can grasp almost physically the difference between analytic and synthetic procedure. The "standard" of science is the system of mathematics; that people agree to it is an accompaniment-the accompaniment of method - of its formal consistency and material applicability, its systematic and empirical import. The corresponding standard in ethics would be a similar system, that is, a formal axiology. Instead of elaborating this central point, Kecskemeti, like so many other writers in moral philosophy, gets sidetracked by superficial analogies_- "agreements" in science and in morality - and elaborates this tangential issue rather than the central one, neglecting to see a difference in kind and not merely in degree between agreement in science and in morality. Agreement in science is engendered by the formal system by virtue, precisely, of its formality; whereas agreement in morals is an empirical hitand-miss affair based on implicative analytic, and hence facultative, rather than on formal and synthetic, and hence obligatory rationality. The second is expressed by synthetic a priori judgments. The a priori is, precisely, the formal system in question that makes the judgments necessary. "Obligation" is the ethical term synthetic $a$ priori necessity.

Kecskemeti's notion of "standards" is, correspondingly, vague and unstructured. Value standards, as postulates, are a species of the genus "standard," another such 
species being "standards of meaning." Meanings are "relations between organism, situations, signs, and responses or between symbols, properties, and sets of situations, or situations; they are not mental processes either experiences by a subject or communicated by him to a partner." 118

Standards of meaning are either standards of relevance or standards of order. Standards of meaning underline situational meaning; they are relevant to the needs of an organism and lead to biologic or hedonistic responses. Standards of order determine definite tasks, just as standards of relevance do; but the good response is not in terms of some enjoyment, but in solving a problem. These are formal: rules of games, rules of classification, and the like. All standards, the author says significantly, have an "analytic" structure. From a logical point of view they may be considered as "definitions." A standard of relevance defines a kind of situational satisfaction; a standard of order defines winning or losing a game. Rules of language are communicative standards.

Thus the rational matrix of value, for Kecskemeti, is not the pattern of formal logic but one of situational behaviorism dressed in situational "logic," somewhat similar to R. M. Hare's. Yet, in seeing meanings as standards, Kecskemeti is far advanced on the road to value cognition. All that would be needed to leap the gap to formal axiology would be to take seriously this nature of meaning and combine it with its logical nature as intensions of concepts. The result would be conceptual intentions used as value standards-precisely the axiom on which formal axiology is built.

The works discussed thus far raise the question of the rational character of value judgments on principle. A number of writers address themselves to this problem from a naturalistic point of view, but without making valuation a subject of natural science.

C. I. Lewis ${ }^{119}$ intends to discover a rational pattern for value judgments. He understands that what is needed is a complete etiology, "a general study of the right and the diverse modes in which right and wrong are judged." But he is not prepared to offer it; it "would represent an incomparably greater undertaking, hardly to be accomplished except by embracing an adequate theory of all the normative disciplines." ${ }^{120}$ Hence, he presents some observations relating to ethics. "The morally right is one species of Right and cannot be identified with right in general." Thus he establishes clearly the difference between ethics and axiology and guards against the moral fallacy.

The Right is established on a rational basis, Lewis believes. "To say that a thing is right is simply to characterize it as representing the desiderated commitment or choice in any situation calling for deliberate decision. What is right is thus the question of all questions." ${ }^{21}$ Lewis locates the right in the process of situational deliberation. With this starting point he already cuts himself off from exact logical analysis of the right for the reason that "situational deliberation" is an analytic and not a synthetic concept and hence admits of no exact systematic treatment. Lewis does not even propose the kind of empirical exactness offered by R. B. Braithwaite, or Donald Davidson and Patrick Suppes. Rather, his instrument is the vague kind of 
pragmatic "logic" introduced-together with the corresponding style—by John Dewey. Although Lewis recognizes that value judgments are not merely interjections, the logical instrument to understand them is vague (and at times ponderous).

It is activities determined directly or indirectly by deliberation and decisions, together with what flows from them, for which we are properly accountable and to which criticism is properly addressed. And each and every such piece of our conduct, mental or physical, is either right or wrong. ${ }^{122}$

Right or wrong is "whatever is decideable or can be determined by deliberation." There are principles of normativity that determine deliberation, and hence are constitutive of judgments of right or wrong. In inductive reasoning, for example,

no inductive conclusion is well taken and justly credible unless the obligation to muster all the given and available evidence which is relevant to this conclusion has been met....Indeed, this principle of the required completeness of available and relevant evidence for the justified credibility of inductive conclusions has a character which is plainly akin to the moral. ${ }^{123}$

It has the character of a maxim.

It calls upon us to be objective-minded, 'reasonable,' 'fair,' willing to give as much weight to what the opposition may put in evidence as to that which we advance ourselves. It demands that respect for facts as such prevail over any wish or subjective inclination....Almost we may say that one who presents argument is worthy of confidence only if he be first a moral man, a man of integrity, prepared not only to tell the truth and nothing but the truth but also the whole truth as he knows it. ${ }^{124}$

Lewis here says, in effect, that the kind of thinking that determines moral action is moral thinking. This is not quite sufficient for an analysis of what moral thinking really is. Needed is, precisely, a determination of "reasonable," "fair," "moral" in terms of some coherent theory. To determine "right" in terms of "moral" is, again, to define ignotum per ignotius. The result of Lewis's analysis is, then, that right and wrong are embedded in a "normative" matrix, whose nature, however, is as obscure as that for which it is to account.

He then proceeds to apply these "normative" principles to conduct. Conduct consists of actions, and actions are distinguished by their consequences. "Any consideration of an act has no content except the predicted consequences of it," and the consequences may be good or bad. Lewis's definition of goodness is "that quality of passages of experience by which he who experiences them finds them satisfying and such as he would prolong." 25 Thus, the ground for choosing the right course of action is the hedonistically interpreted goodness of its consequences. But the predic- 
tion that an act will produce the maximum amount of good consequences is only "the minor premise" of the moral syllogism. The major premise is some valid rule or principle that can select among the many goods possible-personal and social, inherent and instrumental, and so on. The search for such a principle, whose own validity as right is "the deepest-going and the most difficult of all questions concerning right and wrong," leads Lewis to the "Law of Objectivity":

So conduct and determine your activities of thinking and doing, as to conform any decision of them to the objective actualities, as cognitively signified to you in your representational apprehension of them, and not according to any impulsion or solicitation exercised by the affective quality of your present experience as immediate feeling merely. ${ }^{126}$

In simpler language, this means, "Be rational and not emotional."

Lewis belabors and brings forth the oft repeated principle that man, to be a good man, ought to be a rational being, that is, fulfill his definition. This insight in a systematic ethics ought to be at the beginning, and its validity ought to be on the basis of a formal axiology. But, just as Lewis offers the matrix of deliberation instead of a genuine systematic frame of reference for right and wrong, so he offers the validity of an ethical axiom "as valid and itself right" instead of the validity that such an axiom is itself to establish. The validity of an ethical axiom can only be established by axiology; it is axiological validity. The validity that the axiom itself is to establish is ethical validity, the "deepest going and most difficulty question," cannot be answered unless the fundamental relationship between ethics and axiology is determined. This is precisely what Lewis says he is not prepared to do. Lewis's proposal suffers from its own self-imposed limitation, and its failure arises from his refusal to face the issue.

Unfortunately, no more penetrating attempts by naturalists, in the second post-Moorean period, anchor valuation in rationality. Both material and formal naturalists take too much of rationality for granted to subject it to the kind of profound critical examination we find with philosophers and scientists in natural science. Even in the first post-Moorean period, no methodologically profound attempt was made - not excepting the prodigious effort of Lewis himself ${ }^{27}$ - to counter Moore's naturalistic fallacy by a formal rather than a material attack. Although value was not regarded as an object of natural science, the formal categories devised for it, such as Lewis's extrinsicness, inherence, and intrinsicness of value, or the ontologicophenomenological categories of Nicolai Hartmann, were too material, in the sense of G. E. Moore, not to be counted as naturalistic.

In the second period, many fractional accounts of the rationality of valuation were given, justifying this rationality from a variety of view-points. A. C. Ewing ${ }^{128}$ restates his criticism of both naturalism and subjectivism on the basis of his own earlier definition of "good" - the non-naturalist character of which, it is true, is open to doubt; and he criticizes in general the attempt of naturalists and subjectivists to 
represent their views as an analysis of, and not a contradiction of, common sense ethical judgments. He is convinced that even if ethics has a logic of its own, this is not too different from ordinary logic. This conviction is shared by Henry Margenau, ${ }^{129}$ whose appeal to the syllogistic conventionality of legal judgment is out of date. ${ }^{130}$

C. A. Baylis ${ }^{131}$ shows that some value judgments-those that affirm that the pleasantness of an experience is good-can be confirmed in much the empirical way in which scientific judgments are confirmed.

Warner A. Wick ${ }^{132}$ holds that moral philosophy can be "revived" if we regard moral rules as rationally criticizable but imperfectly formulable, in a manner like that "by which we criticize and try to state the generic rules of logic," such as the principle of contradiction. According to these principles, we construct systems that are rational, if anything is; yet, they are not cognitive. The rational and the cognitive differ, and not all that is not cognitive is emotive. Maybe this is another approach to my own solution, which finds the alternative to empirico-analytic naturalism and pragmaticoirrational subjectivism in the axiomatic structure of formal systems. For what is rational though not cognitive if not axioms? For Wick, moral rules and maxims, and the principles that govern them, have rational grounds even though they are not "cognitive" in the narrow sense.

J. O. Urmson ${ }^{133}$ similarly holds that there is no reason to condemn ethical reasoning simply because it does not follow the standards set by either deductive or inductive logic. Our conception of what is valid and what is invalid in ethical reasoning must be derived from a study of ethical reasoning. It is no more possible for all ethical arguments to be invalid than for all men to be small men. If according to some logic this should be the result, then so much the worse for the logic. According to $\mathrm{H}$. J. Paton, ${ }^{134}$ the emotive theory discredits ethics; and the moral attitude is intrinsically rational. For J. D. Mabbott ${ }^{135}$ the subjectivist analysis of moral judgments is contrary to normal usage. The "meanings" it attaches to them are not the ones meant by these judgments. When we compare different such judgments we use procedures that imply objectivity.

An attempt to deduce a system of value from a system of logic, or at least of epistemology, is William H. Werkmeister's. ${ }^{136}$ His proposed value theory is based on an epistemological analysis of first person experience as a bipolar structure between the subject and the object of knowledge. He extends his earlier analysis of this experience ${ }^{137}$ and its application to natural science ${ }^{138}$ to moral science. Werkmeister believes that such a rigoristic approach to value theory - analogous in method to natural science-will have results analogous to that of natural science. It will assign to each of the value terms - "value," "good," "right," "ought"—a uniquely significant place and thus provide a systematic interpretation of all relevant data adequate to the facts of value experience. Werkmeister sees very clearly the necessity for and the advantages of a truly systematic approach to valuation. The mere conception of such a system, I believe, establishes value theory as an independent branch of knowledge and forbids any reduction of value terms to naturalistic terms. Yet, Werkmeister's empirical view of science prevents him from truly executing this 
program. In illustrating his view by a moral example, Werkmeister defines "will" somewhat naturalistically, as including inclinations, intentions, and the like, and betrays a tendency to psychology and anthropology that increases as the theory progresses. A good will is one tending to realize the highest values possible in any given situation. This definition depends on the axiological definition of value-in-general; and its definition, Werkmeister believes, must be empirical "since our theory is to be an interpretation of value phenomena." Although he made clear in his philosophy of science the essential role of formal systems, ${ }^{139}$ Werkmeister fails to take this seriously in his value theory.

The founders of natural science, Sir Isaac Newton, Galileo Galilei, Niels Bohr, and others, he says, proceeded "empirically." But this is not the primitive empiricism of sense observation, which only served to precipitate the formula that gave the clue, opening up the Sesame of the system and letting the inquirer enter into it. The first-person experience on which Werkmeister insists in his philosophy of science is, precisely, the great experience of genius in discovering a system. Werkmeister begins his value theory with the data of first-person experience, but in a peculiar way. The "object" involved in value experience is for him not value, as a strict scientific analogy would require, but any object that evokes value. With this emphasis on the evocation of value rather than value itself as the object of axiology, Werkmeister's theory leads toward naturalistic views such as C.I. Lewis's and others. Borrowing from Lewis the distinction between intrinsic, inherent, and instrumental value, Werkmeister's theory develops by means of symbolic schemata which represent first-person experiences; but they cannot be more revelatory of value than this experience itself, that is, the experience of value evocations. In a strict analogy to natural science, they are to axiology as the signs of the zodiak are to astronomy.

Without a formal system - a constructive axiomatic rather than an abstractive schematism - no practically efficient axiological science can be established. Therefore, "applications" of such schemata to practice lack necessity and coherence. Ralph Barton Perry, ${ }^{140}$ applying his concept of "interest" to the human pursuits and institutions that make up civilization, is much less structured than Albert L. Hilliard's and F. S. C. Northrop's similar attempts, but he proceeds on the basis of analytically much better structured concepts.

The difficulty of establishing an independent axiological system as universal and precise as the mathematical system of the natural science has led some axiologists to a methodological tour de force: using the terminology and method of already existing value sciences as models for axiology. This is putting the cart before the horse and employing the prescientific Aristotelian procedure characterized above of using the explicandum as the explicans. Supposing that general theory of value is that by which theories of specific values are to derive their meaning and validity, it is methodologically illicit to reverse the procedure and derive the meaning and validity of general theory of value from the theory of a specific value.

Such procedures, long since overcome in natural philosophy, are quite frequent in contemporary moral philosophy, not only in material but also in formal naturalism. 
Their suggestiveness and intellectual ingenuity must not blind us to their fundamentally mistaken methodological basis. Thus, W. D. Lamont founds his analysis of the value judgment on the terminology and procedure of economic science, ${ }^{141}$ in a manner similar to, though more systematic than, the one in which he had earlier related the moral judgment to jurisprudence. ${ }^{142}$ William Kneale, Stephen E. Toulmin, and Héctor Rodríguez base axiology on jurisprudence, and F. S. C Northrop and Henry Margenau have drawn analogies between axiology and jurisprudence. Historically, human law is based on the law of nature, that is, the rationality of the universe. Without faith in this rationality no human system is possible.

The difference between value and moral judgments, according to W. D. Lamont, lies in the respective personal and inter-personal reference of the two kinds of judgment. Valuation is choice; it is concerned with the correlation of ends within a total personal conception of "the good." Moral judgments, being the assertion of duties or obligations, carry a reference to the conception of "right" and therefore to an inter-personal order. Value judgments may be called an "economic" assessment of modes of action, while moral judgments involve a "juridical" assessment. The theory of value judgments thus is concerned with matters common to ethics and economies, the theory of moral judgments with matters common to ethics and jurisprudence. ${ }^{143}$

Value judgments are not, strictly speaking, about things and their qualities. They are, rather, about their being, maintenance, and destruction. References in the content of value judgments are to "ends" or some "end." They indicate a state of affairs that the judger has a disposition to bring into existence, maintain in existence, allow to go out of existence, or destroy. They appear to be primarily, though never entirely, the expression of a conative disposition, or of a "demand." To call something good is to express approval, to express the disposition to create or maintain it in existence. While the simple positive value judgment " $\mathrm{X}$ is good" expresses a demand or conative disposition to maintain something in existence, a "comparative" value judgment is an expression of "choice" when objective circumstances, for the moment beyond our control, enforce on us the necessity of renouncing one thing if the other is to be attained. Thus, "valuation" implies conditions of "scarcity," and in this way the field of valuation is identified with that of economics, in a way similar to that in which Glansdorff, in a different context, identifies it with the biological theory of adaptation - another proof that what unites and what divides value theories is method and not content.

W. D. Lamont's first propositions are similar to Glansdorff's principles: "Valuation is always relative or 'comparative' never absolute or 'simply positive.' Value is attributed to the non-existent, never to the existent."|44 His subsequent propositions use the terminology of economics. His ultimate grounds for the attribution of goodness sound biological rather than economic: "The ultimate ground of all attribution of goodness is the existence in our nature of certain activity-patterns which are not teleological but organic." 145 On this organic matrix the economic-valuational activity is built up. A value judgment in its simplest form is a mere attribution of 
goodness rather than an attribution of degrees of goodness. It is what the economist would call an expression of "want" or "desire."

It is that psychical attitude in virtue of which the economist attributes 'desiredness' or 'utility' to that to which the attitude is directed. It is a psychical state with the emphasis on the conative disposition towards the creation or maintenance of a state of affairs. ${ }^{146}$

It is "demand" in the general sense. But any particular attribution of goodness, or demand in this general sense, remains

devoid of practical effect if it stands in competition with other demands of the same subject, the objective conditions rendering necessary a choice between the two or more things demanded. Such enforced choice means enforced 'valuation,' the placing of the alternatives in an order of degree of goodness. ${ }^{147}$

The ultimate ground of the attribution of goodness (the "simply positive value judgment") is the existence in our nature of certain organic activity-patterns, but the ultimate ground of our comparative value judgments - those which normally determine what we effectively regard as good-lies in the principle of Economy. "This is the principle whose operation is popularly described as the search for happiness." 148 It is that principle in our nature that makes us integrate our different conative dispositions in the pursuit of "what is good on the whole." 149

While Lamont, in an ingenious way, takes economics as the model of axiology, William Kneale $e^{150}$ uses the law. His legal analogy is interesting in comparison with H. L. A. Hart's ${ }^{151}$ entirely different account of the same analogy. Kneale thinks that words such as "ought," "right," and "wrong," far from being unanalyzable, are, on the contrary, obviously analyzable; and their moral use can be explained in the same way as the use of the same words in legal discourse. As used by both lawyers and moralists, the word "right" is equivalent to the phrase "in accordance with the law," only that in the case of the moralist the law referred to is the moral law. When Mrs. A. seeks the advice of her minister about what (if anything) she should do concerning her boarder, Mrs. B., whom she suspects of being unfaithful to her husband-a prisoner-of-war in a foreign country, she fully expects him to begin his part of the conversation by shaking his head and saying "Tut,tut." But that is not all she wants to hear from him. When he tells her "You ought to do X," he purports to tell how the moral law applies to her case, and this is what she wants him to do. There is a close analogy, then, between the ways in which the lawyer and the moralist use such words such as "right." There was a time when no one made a sharp distinction between the moral law and the law of the land, but people spoke simply of the Law.

The question then comes down to, "What is the moral law?" Kneale gives four features of it: the moral law (1) is supposed to be stricter than the law of the land, and (2) is thought to differ from the law of the land in having no sanction. (3) Those who 
have attained a clear notion of the moral law think of it as a system of orders that they themselves concur in giving, and (4) the moral law is thought to be a set of commands that all reasonable persons who possess the relevant information must concur in giving to themselves and their fellow human beings. Reasonableness, the last feature, which makes people legislators of the moral law, is something more than rationality. It means willingness to consider reason and to modify our own preferences.

The subjectivist may oppose that the moral law is not objective since it cannot be ascertained in a purely intellectual fashion as the law of the land may be. Obviously, Kneale argues, the moral law cannot be objective in the same sense as a fact or a law of natural science. The word "objective" rather means something like "impartial," "free from bias," "independent of personal taste," or, more explicitly, "common to all reasonable persons." We cannot speak of John's moral law or Smith's moral law. In this sense, the moral law is objective by definition. Kneale does not discuss the systematic structure that this moral law could or should have or elaborate its analogy to positive law, to natural law, or to mathematics. If there is a moral law, it must be possible to define its terms, "morality," "value," and such, as elements of a strict system. Kneale, as against both Herbert Feigl and Paul Kecskemeti, whose theories resemble his, is convinced that there is such a system, even if he cannot define it and must fall back, for the content of the law in each particular case, on the context in question. Kneale appeals to the law because of its universal nature.

Stephen E. Toulmin ${ }^{152}$ appeals to the law for the very opposite reason, its pragmatic nature. If there is to be a pattern for axiology, it cannot be the formal one of mathematics or that of traditional logic. The formality of these patterns cuts them off from practical use. Hence jurisprudence rather than mathematics should be the axiologist's and even the logician's model in analyzing rational procedures. This tour de force is based on the pseudo-Wittgensteinian misunderstanding of the scientific method, at least in fields still philosophical, and of the nature of systems in particular. Their formality is precisely what makes systems practically effective, and no other genuine effectivity exists in natural and, as far as we know at present, human affairs. Jurisprudence, Toulmin's model, is itself painfully aware of its pragmatic shortcomings, and the trend in it is toward the kind of systematicness that Toulmin counts upon jurisprudence to overcome, as in the works of L. Straus, Leonard Nelson, and Eduardo García Máynez. ${ }^{153}$ Toulmin is like a drowning person desperately grabbing at a life-saver that has been thrown away because it will not float.

Héctor Rodríguez has a third reason for using jurisprudence as a model for axiology. He sees rightly that a scientific ethics cannot be based on religion or metaphysics. The subject matter of ethics is humankind, which means both the individual person and the totality of all persons - seen under the viewpoint of the will. This totality is essentially a juridical one because the free agreement of responsible persons is the relation of contract, and this relation is the basis both of the law and of ethics. The juridical order thus turns out to be the objective order of ethics, and goodness becomes equivalent to justice. The danger of constructing the 
injustice of a legal order as justice, and hence evil as good, he counters by fusing the concept of science with that of ethics: goodness or justice cannot be autocratic for this would presuppose the contradiction of an absolute scientific knowledge. Scientific knowledge is by its nature democratic, that is, relative and progressive. Insofar as ethics is scientific-and a scientific ethics is Héctor Rodriguez's premise - it cannot be autocratic or absolute. As is clear, this axiology is, of the three juridical foundations mentioned, closest to Kant's. It also suffers from the same shortcoming as Kant's: that the moral law, the ethico-legal order in itself lacks a criterion for good or bad. The scientificness of the discipline that deals with this order, ethics, does not guarantee, much less establish the scientificness of the order dealt with. This is the fallacy of method we have so often encountered.

Jurisprudence and economics are not the only specific value disciplines used as models for general theories of value. Such models have been found in general theories of culture, ${ }^{154}$ social science, ${ }^{155}$ evolutionary theories, psychology, anthropology, indeed, as we have seen previously, there is no field that cannot, and for which, some of their devotees would not, be regarded as the value field par excellence. ${ }^{156}$ The only such field missing at present is that of value itself. There is no general theory of value which elaborates Value itself independently of anything that is valuable, and this goes for naturalistic as well as for non-naturalistic "value" theories. Moore's fallacy is all-pervading: Value itself is, in every value theory up to now, identified with something that is valuable; the species is taken for the genus. The only way out of this predicament is a formal axiology.

The naturalistic theories examined in this section are not formal in the logical sense: they do not regard value phenomena as subjects of some natural science. Values for them are naturalistic phenomena in the sense of Moore. They do regard them as subjects of some method analogous to that of natural science, and "natural science" is conceived here in all kinds of manners, from the most empirical to the most formal (as by Margenau). Value itself is conceived either as a naturalistic phenomenon, such as choice, preference, desire; or as a pseudo-formal phenomenon, such as agreement or objectivity; or as a valuational phenomenon in the narrow sense, such as duty, the Golden Rule, and so on. All these theories, then, "formal" as they are in the sense defined, are tied to some content. Let us now close our account of the naturalistic formalists with some theories that abstract somewhat more from material content, even though none do so to such a degree as to lose their naturalistic hue.

Here belong, first of all, the cooperative inquiries edited by Ray Lepley. ${ }^{157}$ The first of these discusses four questions posed by John Dewey, namely (1) What connection is there, if any, between an attitude that may be called prizing or holding dear and desiring, liking, interest, enjoying? (2) Is a judgment of valuation a necessary condition for the existence of values? (3) Does anything in the nature of evaluations as judgments mark them off from other judgments? (4) Is the scientific method, in its broad sense, applicable to judgments of valuation? The contributors agree on an empirico-naturalistic interpretation of value phenomena, yet do not regard these 
phenomena as the same that are dealt with by natural science. They are all for the application of the method of natural science-narrowly empirically conceived- but not its content. "The cause we plead is the cause of a science of valuation, which is possible only if our value-terms are given definite descriptive meaning." The second inquiry covers the whole gamut of value language, from empirical description to formal construction. ${ }^{158}$

Less elaborate but no less definite proposals for empirico-naturalistic axiologies on a more or less formal basis are T. Czezowski's, Meckler's, and Carl Cohen's. Czezowski ${ }^{159}$ regards moral principles as generalizations of individual acts of appreciation that are communicable, verifiable, and can be known empirically in a way that differs in nothing from the empirical knowledge of natural science. The position reminds us somewhat of Sören Halldén's. ${ }^{160}$ Meckler ${ }^{161}$ attempts to show that in principle value judgments may be translated into factual sentences. No universally acceptable characterization of "value" is possible, but the assumption that $x$ is valuable if and only if $x$ ought to be done seems compatible with all major theories of the "good." Thus, $x$ is valuable implies that $x$ is produced by some possible human action: "ought" implies "can." Hence, both value-producing events as well as the events valued are describable and can both be treated as "facts." The claim that the ultimate cause of these actions differs from the usual "physical" causes, that it is "noumenal" or "final," is found wanting, as is the view that human actions cannot be scientifically predicted, hence that the realm of science cannot intrude upon the "realm of value."

But what kind of facts are values? Evidently, behavior in agreement with the "moral" always results in events approvable by the judgers. ${ }^{162}$ Ascription of "morality," of "value," occurs where there is approval or satisfaction in such judgers. Even though the conditions under which these approvals and satisfactions happen are very varied, they are yet all factually describable. It is no counterargument to say that science may describe but not prescribe. Prescribing presupposes a wanting, a valuing; science is a method, not a wanting. Meckler's proposal, thus, comes down to a psychological theory based on the teleological interpretation of "ought." It somewhat resembles Rapoport's.

Carl Cohen ${ }^{163}$ suggests a formal frame of reference for naturalistic axiology, based on semantic analysis. From the "eulogistic-dyslogistic" axis of word choices, as illustrated in Bertrand Russell's "conjugation": "I am firm," "You are obstinate," "He is a pig-headed fool," Cohen concludes that value attitudes may be identified by such analysis. This analysis may be refined in a "vector analysis of value judgments." We may regard the value universe as a unit circle with the highest good located at $90^{\circ}$ and the lowest evil at $270^{\circ}$ and determine any location within the circle with reference to these points. The scheme reminds us of Khouteck's diagram, discussed by Nicolai Hartmann ${ }^{164}$ in connection with the Aristotelian mean. It is naturalistic in the sense of referring to attitudes, but it abstracts so much from these attitudes as to be almost purely formalistic. The difference between a naturalistically 
formal and a purely (non-naturalistically) formal axiology is supplied by Cohen himself in his formal theory of Goodness.

Let us now turn to these theories. 